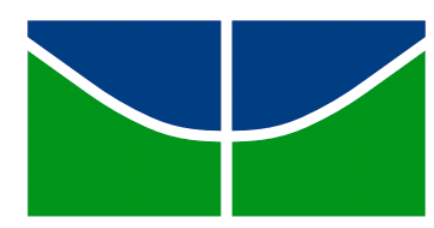

UNIVERSIDADE DE BRASÍLIA INSTITUTO DE

CIÊNCIAS BIOLÓGICAS

PROGRAMA DE PÓS-GRADUAÇÃO EM ECOLOGIA

VIVER NO CAMPO OU NA CIDADE? RESPOSTA DOS MORCEGOS (MAMMALIA, CHIROPTERA) À ANTROPIZAÇÃO DA PAISAGEM

\author{
DÉBORA ISAURA DE MACEDO
}

BRASÍLIA, DF 2015

VIVER NO CAMPO OU NA CIDADE? RESPOSTA DOS MORCEGOS (MAMMALIA, CHIROPTERA) À ANTROPIZAÇÃO DA PAISAGEM

DÉBORA ISAURA DE MACEDO 
Orientadora: Prof. Dr. Ludmilla M. S. Aguiar

Dissertação apresentada ao programa de Pós-

Graduação em Ecologia do Instituto de Ciências

Biológicas da Universidade de Brasília como requisito

parcial à obtenção do título de Mestre em Ecologia

DÉBORA ISAURA DE MACEDO

\section{VIVER NO CAMPO OU NA CIDADE? RESPOSTA DOS MORCEGOS (MAMMALIA, CHIROPTERA) À ANTROPIZAÇÃO DA PAISAGEM}

Data da defesa: 31/07/2015 Nota:

\section{BANCA EXAMINADORA}

Prof. Dr. Ludmilla M. S. Aguiar

Departamento de Zoologia - Universidade de Brasília

(Orientadora)

Prof. Dr. Maria João V. C. Ramos 
Departamento de Ecologia - Universidade Federal do Rio Grande do Sul (1ำ Titular)

Prof. Dr. Emerson M. Vieira

Departamento de Ecologia - Universidade de Brasília ( $2^{\circ}$ Titular)

Prof. Dr. Gabriela B. Nardoto

Departamento de Ecologia - Universidade de Brasília (Suplente)

\section{AGRADECIMENTOS}

Agradeço em primeiro lugar a Mãe natureza por me permitir estuda-la e muitas vezes até agredi-la por um ideal maior. Agradeço-a por me proporcionar momentos incríveis durante este período da minha pesquisa, todos os pôr do sol, a vegetação e os animais encontrados. Um contato único com o Cerrado, manifestação do Divino em minha vida.

Agradeço meus pais, Cleonice e Geovani, por me ensinarem o amor e respeito á natureza. Com eles aprendi a ser uma verdadeira Bióloga, mesmo antes de me decidir trilhar este caminho. Bem como agradeço minha pequena grande família, Bárbara, Bernardo e meu amado filho, por me darem forças, mesmo que inconscientemente, para continuar e finalizar este trabalho com toda dedicação. Agradeço também, meus queridos, Vital e Helen, por todo apoio em todos os sentidos inimagináveis.

Agradeço meus amigos de laboratório, Elba, Daniel, Thales Aspira, Pedro, Paula. e Thales, toda ajuda e incentivo, sem os quais, afirmo com certeza, não chegaria até o fim desta jornada. Especialmente ao Thiago, Elba pela ajuda constante no campo e companhia no laboratório, sem contar toda a diversão proporcionada por eles. E ao Daniel, pela ajuda intelectual e as boas risadas. Agradecimento mais que especial ao Renato, meu companheiro de todas as horas, o qual sempre me mostrou a direção, quando me perdia no caminho. Agradeço ao Vandélio, que nos conduziu aos locais de coleta com toda disposição e segurança, além de ser uma companhia maravilhosa. Aos meus companheiros de turma, responsáveis pela diversão e descontração nos possíveis momentos. Em especial a Tânia e a Mari, que tomaram um lugar importante na minha vida pessoal também.

Agradeço a minha orientadora Ludmilla Aguiar, por toda estrutura física cedida, todos os materiais que tornaram tudo possível e principalmente pelo incentivo, inspiração e dedicação para com o meu trabalho. A Gabriela Nardoto, por todo apoio, disponibilidade e ensinamentos. E a todos os professores que de alguma forma me ensinaram e me inspiraram.

Agradeço a Juliana, Renatinha, a Dani e ao Leleco, pela ajuda estatística e dúvidas retiradas. 
Por fim, agradeço a todos que tornaram essa vitória possível e a todos que acreditaram em mim e na minha capacidade como pesquisadora.

\section{SUMÁRIO}

\section{ÍNDICE DE FIGURAS}

Figura 1. Porcentagem das características de uso do solo da matriz circundante aos oito remanescentes de cerrado sensu stricto do Distrito Federal, em um buffer de raio de $3.5 \mathrm{~km}$, tomado a partir da borda de cada fragmento ...................35

Figura 2. Dendrograma de similaridade entre os tipos de uso de solo das matrizes adjacentes aos oito fragmentos de Cerrado sentido restrito no Distrito Federal. Os fragmentos inseridos em matriz urbana são: CO (U1), Aeroporto (U2), Jockey (U3) e os fragmentos inseridos em matriz rural são: Juliano (R1), IBGE (R2), I.F.B (R3), Leite (R4) e E.V.R (R5)

Figura 3. Curva de rarefação de espécies de morcegos dos fragmentos inseridos empara as matrizes urbana e rural em fragmentos de cerrado sensu stricto no Distrito Federal- DF

Figura 4. Escalonamento multi-dimensional não métrico (NMDS, do original em inglês) das composições das espécies de morcegos em cinco fragmentos de matriz rural (círculos pretos) e três fragmentos de matriz urbana (círculos vermelhos). As diferentes siglas são as espécies (S.I=Sturnira lilium, M.t = Molossops temninckii, P.h=Phyllostomus hastatus, G.s=Glossophaga soricina, A.l=Artibeus lituratus, E.d=Eptesicus cf. diminutus, P.I= Platyrrhinus lineatus, C.p= Carollia perspicillata, L.d= Lonchophylla dekeyseri, A.p=Artibeus planirrostris, G.b=Glyphonycteris behnii A.c= Desmanura sp., P.d= Phyllostomus discolor, A.g= D.s= Desmodus rotundus, C.v=Chiroderma villosum, C.p1= Cynomops planirrostris, C.d= Chiroderma doriae $)$. 36

Figura 5. Valores de $\delta^{13 C}$ e ao $\delta 15 \mathrm{~N}$ das guildas de morcegos em ambiente urbano e ambiente rural para morcegos frugívoros (A), nectarívoros (B), insetívoros (C), e onívoros (D) 50

Figura 6. . Boxplot dos morcegos fitófagos em relação á fonte alimentar ( ${ }^{13 \mathrm{C})}$ (gráfico "a") e ao nível trófico $\delta 15 \mathrm{~N}$ (gráfico "b"), em remanescentes de Cerrado inseridos em matriz urbana e rural do Distrito Federal 
Figura 7. Boxplot dos morcegos animalívoros em relação á fonte alimentar $\left(\delta^{13 C}\right)$ (gráfico "a") e ao nível trófico $\delta 15 \mathrm{~N}$ (gráfico "b") em remanescentes de Cerrado inseridos em matriz urbana e rural do Distrito Federal

Figura 8. Gráfico de dispersão das guildas de morcegos de remanescentes de Cerrado do Distrito

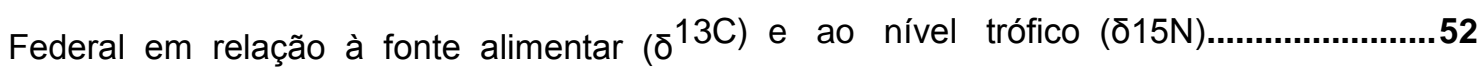

Figura 9. Gráfico de dispersão dos morcegos divididos em guildas de animalívoros e fitófogos em relação àfonte alimentar $\left(\delta^{13 C)}\right.$ (gráfico "a") e ao nível trófico $\delta 15 \mathrm{~N}$ (gráfico“b”). 68

Figura 10. Espécies de morcegos de fragmentos de Cerrado do Distrito Federal em relação ao hábito alimentar, mensurado por meio da origem alimentar $\left(\delta^{13 C}\right)$ (gráfico "a") e do nível trófico $(\delta 15 N)$ de cada espécie 68

\section{ÍNDICE DE TABELAS}

Tabela 1. Distribuição da abundância das espécies de morcegos em fragmentos de Cerrado inseridos em matriz urbana e rural no Distrito Federal. Os morcegos foram divididos em guildas alimentares e separados por família 37

\section{INTRODUÇÃO GERAL}

\section{Uso da terra e fragmentação de hábitat}

Os ecossistemas naturais vêm sofrendo grandes transformações devido à expansão das populações humanas (Vitousek et al. 1997). Essas transformações se manifestam na perda de habitat e na fragmentação de extensas regiões da vegetação nativa (Vitousek et al. 1997, Fahrig 2003). A fragmentação de habitat tem sido uma das maiores ameaças para a biodiversidade global, resultando em grande perda de vegetação nativa e modificação da paisagem (Erlich e Wilson 1991, Vitousek et al. 1997). Fragmentos de habitat originados a partir de um processo antrópico podem aumentar a simplificação espacial da mancha de habitat, assim como a escassez de recursos naturais essenciais às espécies residentes. Essa simplificação e consequente escassez de recursos representa uma maior ameaça à viabilidade das populações podendo em casos extremos levar à extinção de espécies (Forman e Godran 1981, Sala et al. 2000).

A fragmentação de habitat pode ser definida como a transformação de uma paisagem extensa e contínua em várias manchas, ou fragmentos de menor tamanho, isoladas por uma matriz de habitat dissimilar (Wilcove et al. 1986). Porém, há várias definições de fragmentação. Os conceitos são dependentes de diversos fatores, individuais ou associados, tais como: o tempo do processo de fragmentação, a matriz adjacente às manchas, ou mesmo a escala de estudo, que deve ser 
determinada de acordo com a capacidade de dispersão do organismo em questão (Fahring e Merrian 1994, Fahring 2003, Estrada-Villegas et al. 2010). Além dos processos antrópicos por urbanização, estabelecimento de agricultura e estradas, o fragmento pode ser interrompido naturalmente, por exemplo, por corpos d'água ou montanhas (Viana 1990). No contexto do presente trabalho, defino o fragmento de acordo com Cullen-Jr (2003), ou seja, como uma mancha de vegetação gerada por alteração de origem antrópica.

O processo de fragmentação é composto por alguns elementos que compõem a paisagem. Forman e Godron (1986) classificaram esses elementos como matrizes, manchas ou corredores. A matriz é aqui definida como a porção-não habitat, no qual o fragmento está inserido, influenciando a dinâmica da paisagem (Metzer 2002). As manchas podem apresentar vários tamanhos e formatos, e podem mudar ao longo do tempo. Além disso, podem diferir uma das outras por gradientes bióticos e abióticos, o que pode ser atribuído a consequências do uso da terra por humanos (Bowers e Matter 1997). As manchas criam paisagens que são diferentes em estrutura, já que algumas são próximas umas das outras e têm alta conectividade, enquanto outras estão mais distantes e com alto grau de isolamento (Bowers e Matter 1997).

A presença de determinadas espécies nas manchas pode ser resultado não só do isolamento ou conectividade com outros habitats, mas também do tipo do habitat adjacente (Andrén 1994). O efeito do grau de isolamento e do tamanho da mancha sobre as populações vai depender não só da quantidade restante de habitat original na paisagem, mas também da adequação da matriz que rodeia o fragmento e do que ela oferece aos indivíduos (Andrén 1994). Áreas que são consideradas negativas para a perpetuação de uma determinada espécie, podem ser de ótima qualidade para a perpetuação de outra espécie (Cerqueira et al. 2003).

Vários estudos mostram os efeitos da fragmentação em várias diferentes regiões, com diversos grupos de animais (Saunders et al. 1991, Morato 1993, Andrén 1994, Brooks et al. 1999, Mac Nally et al. 2000, Pavan et al. 2011). os estudos sobre os efeitos da fragmentação de habitat no Brasil têm sido mais comuns em ecossistemas florestais, como a Amazônia (Taddei e Reis 1980, Reis 1984, Bernard 2001, Bernard e Fenton 2002, Bernard e Fenton 2003, Bernard e Fenton 2007, Trevelin et al. 2013, Novaes et al. 2015) e a Mata Atlântica (dos Reis e Muller 1995, Aguiar e Marinho-Filho 2004 , Bianconi et al. 2006 Faria et al 2006, Mello e Schittini 2014). Apesar de serem mais recentes, pesquisas sobre os efeitos da fragmentação de habitat no Cerrado também têm recebido atenção (e.g Marini 2001, Zortéa e Alho 2008, Borges 2008, Carvalho et al. 2009, Calaça et al. 2010, Manica et al. 2010, Corrêa et al. 2011).

Os esforços de conservação dos ecossistemas naturais enfrentam grandes desafios em áreas sob intensa atividade humana, especialmente nas áreas urbanas. Áreas protegidas geralmente são manchas de habitat relativamente pequenas e são fortemente influenciadas pelos habitats urbanos da matriz circundante (Lesiński e Grys 2012). As cidades podem ser úteis para estudos dos efeitos das 
alterações globais sobre as florestas porque fragmentos florestais urbanos estão expostos à condições que as florestas rurais podem enfrentar no futuro (O'Brien et al. 2012).

Assim, estudos que avaliam os efeitos do processo de fragmentação de habitat na sobrevivência e viabilidade das espécies são importantes, principalmente para aqueles organismos que possuem grande potencial de dispersão e capacidade para acessar as áreas da matriz (Norberg e Rayner 1987, Meyer e Kalko 2008). Os esforços de pesquisa precisam ser mais aprofundados, já que não foi verificado ainda um padrão de resposta dos grupos de organismos á fragmentação. Especialmente para os organismos que

possuem capacidade de voo, esta resposta tem sido variada. Por vezes é negativa, gerando queda na abundância e riqueza de espécies (e.g. Maldonado-Coelho e Marini 2004, Faria 2006, Struebig et al. 2011). Outros estudos mostram uma resposta positiva em relação á riqueza e abundância dos organismos (Ethier e Fahrig 2011), e outros mostram um efeito neutro (e.g. Stouffer e Bierregaard 1995, Bernard e Fenton 2003, Bernard e Fenton 2007) ou mostram que a resposta é específica para cada espécie (Willig et al. 2007, Estrada-Villegas e Kalko 2010).

\section{Isótopos estáveis}

Isótopos estáveis são traços bioquímicos que podem promover informações a respeitos dos grupos funcionais e dos hábitos alimentares dos organismos. São instrumentos úteis para um melhor entendimento da complexidade da rede trófica, da intrincada coexistência de espécies e dos mecanismos de manutenção da diversidade de espécies (Ramos R, Gonzaléz-Solís J 2012, My-Y Lam et al. 2013). Isótopos são definidos como átomos de um mesmo elemento químico que possuem o mesmo número de próton $(\mathrm{Z})$, mas diferente número de nêutrons $(\mathrm{N})$, demostrando assim diferentes valores de massa atômica (Pereira et al 2007). Estes isótopos são considerados estáveis, pois não alteram sua massa durante toda sua existência (Martinelli et al. 2009). Os isótopos de um mesmo elemento com menor massa atômica são chamados de isótopos mais leves, enquanto os de maior massa são conhecidos como isótopos mais pesados. Os isótopos mais pesados são mais raros em relação aos mais leves, ou seja, os mais pesados estão presentes na natureza em menores quantidades (Martinelli et al. 2009). A razão entre o isótopo mais leve e o mais pesado é definida como a composição isotópica de cada elemento. A composição isotópica é representada por delta (ס) e cada elemento químico possui um padrão de $\delta$ que o representa (Martinelli et al 2009).

Uma vez que a composição isotópica varia de forma previsível ao se mover pelos compartimentos ecossistêmicos, ela pode ser uma ferramenta para estudos ambientais, pois os valores absolutos de isótopos estáveis podem diferir entre regiões, e entre diferentes habitats dentro da mesma região (Martinelli et al. 2009, Lam et al. 2013). Tanto que nos últimos anos essa ferramenta foi utilizada em estudos avaliando ecologia trófica, comportamento migratório de espécie e estudos da conexão entre populações (Cryan et al. 2004, Kelly 2000). 
Alguns elementos químicos como o oxigênio, hidrogênio, enxofre, carbono e nitrogênio possuem particular importância nos estudos ambientais utilizando isótopos estáveis (Martinelli et al. 2009), sendo carbono e nitrogênio os principais e mais utilizados. No caso do carbono, esta importância se dá pelo fato deste elemento fazer parte de $40 \%$ a $50 \%$ da matéria orgânica viva. A circulação do carbono pelos ecossistemas ocorre por meio de três processos: troca de dióxido de carbono entre a atmosfera e os oceanos; sedimentação de carbonatos; e respiração e fotossíntese (Ricklefs 2001). Estimativas indicam que, a cada ano, cerca de 85 gigatoneladas (Gt) de carbono são assimilados pela fotossíntese realizada na biosfera (Ricklefs 2001). Assim, as plantas, que são a base da cadeia alimentar, se tornam importantes compartimentos de carbono (Ricklefs 2001). Estas plantas podem diferir em relação ao mecanismo fotossintético que utilizam (C3, C4 e CAM) (Mooney e Ehleringer 1997). Cada tipo de planta possui um valor isotópico de carbono característico. Assim, a origem deste elemento na dieta pode ser determinada (Herrera et al. 1993, Martinelli et al. 2009).

A maioria das espécies de plantas dos ecossistemas terrestres é do tipo C3. Nas plantas com este tipo de metabolismo as espécies reduzem o $\mathrm{CO} 2$ a um composto de três carbonos (3-PGA) pela enzima RuBisCO (ribulose bifosfato carboxilase/oxigenase) na realização da fotossíntese (Marzzoco e Torres, 2006). No Cerrado, este tipo de metabolismo (C3) é o utilizado pelas plantas nativas. Várias plantas de clima mais quente modificam sua forma de assimilação do carbono, reduzindo o CO2 a um composto de quatro carbonos (ácido aspártico ou málico) por meio da enzima fosfoenolpiruvato carboxilase (PEP case). Neste caso são chamadas de C4 (Marzzoco e Torres 2006). As plantas C4 existem em menor quantidade, representando $5 \%$ das espécies terrestres. As gramíneas de origem tropical e subtropical, o milho, a cana-de- açúcar e a braquiária são exemplos.

O nitrogênio é um dos elementos mais limitantes da produção primária do planeta (Vitousec et al. 1997). Este elemento compõe estruturalmente as proteínas e ácidos nucléicos, e assim, todos os organismos consomem este elemento em sua dieta (Ricklefs 2001, Begon et al. 2007). A ciclagem do nitrogênio dentro dos ecossistemas é originalmente realizada de três formas: fixação biológica (FBN), mineralização e deposição atmosférica (Bobbink 2010). A FBN acontece quando um novo nitrogênio reativo é introduzido no sistema principalmente por microorganismos vivos. A mineralização é a conversão de compostos de nitrogênio orgânicos para inorgânico dentro do sistema, e a deposição atmosférica acontece quando o nitrogênio é transferido de um sistema para outro (Begon et al. 2007).

Dessa forma, a leitura isotópica do C pode determinar a via fotossintética quando isto é desconhecido para uma espécie. Assim, a partir das informações fornecidas pelos elementos pode ser inferida a origem da dieta de um animal que se alimente de determinada planta (Farquhar et al. 1989). A composição isotópica do $\mathrm{N}$, dentro dos estudos ambientais com isótopos estáveis, traz informação a respeito do nível trófico em que cada espécie se encontra (Martinelli 2009). Esses valores, que determinam a fonte alimentar e o nível trófico dos animais, são específicos para cada região, inclusive para a região do Cerrado (Parron et al. 2004, Bustamante et al. 2004). 
Para morcegos, a análise de isótopos estáveis de carbono e nitrogênio tem sido usada frequentemente para avaliação da dieta e ecologia alimentar destes organismos em vários contextos (Fleming et al. 1993, Des Marias et al. 1980, Mizutani et al. 1992, Herrera et al. 2001, Schondube et al. 2001, Hobson et al. 2001, Herrera et al. 2002, Voigt et al. 2003, York e Billings 2009, Lee e McCracken 2005, Voigt e Speakman 2007, Salvarina et al. 2013, Lam et al. 2013, Dammhahn e Goodman 2014, Salgado et al. 2014). Estes trabalhos mostram que a análise isotópica é uma técnica extremamente eficiente para estudos mais refinados de ecologia trófica.

\section{Cerrado}

O Cerrado é considerado um bioma de grande importância biológica devido a seu valor em termos de diversidade biológica e endemismo (Klink e Machado 2005). Originalmente cobria cerca de dois milhões de $\mathrm{km}^{2}$ e representa $23 \%$ da área total do Brasil (Ratter et al. 1997) ou 204,7 milhões de hectares (IBGE 2004). É considerado um dos 34 hotspots mundiais para a conservação, devido à relação diversidade, endemismo e alta pressão antrópica (Myers et al. 2000, Mittermeier et al. 2004). Este bioma está presente em 11 estados brasileiros: Bahia, Goiás, Maranhão, Mato Grosso, Mato Grosso do Sul, Minas Gerais, Paraná, Piauí, São Paulo e Tocantins e Distrito Federal.

Sua formação é similar a de uma savana tropical (Eiten 1993, Ribeiro e Walter 2008). Savana tropical é o nome dado a uma região cuja vegetação predominante é gramínea, com árvores esparsas e arbustos, isolados ou em pequenos grupos (Ribeiro e Walter 2008). A savana é o bioma típico das regiões de clima tropical com estação seca (Eiten 1993, Ratter et al. 1997, Ribeiro e Walter 2008). A vegetação típica no bioma Cerrado é composta por espécies adaptadas a solos bem drenados, e matas ciliares a seguir os cursos de água (Ratter et al. 1997). O Cerrado possui um gradiente de formas, que variam em número de estratos e cobertura foliar, indo desde campos naturais até florestas densas com a altura do dossel de 12-15 m (Ratter et al. 1997). Este bioma consiste em muitas espécies de gramíneas e ciperáceas, misturadas com uma grande diversidade vegetal, sendo famílias particularmente importantes as Leguminosae, Compositae, Myrtaceae e Rubiaceae (Ratter et al. 1997).

O Cerrado possui a estruturação da paisagem naturalmente heterogênea, composta por um mosaico de subunidades de vegetação natural, originada por fatores edáficos, diferenças geomorfológica, topográficas e climáticas (Ribeiro e Walter 1998). Porém, grande parte destas áreas naturais está sendo transformada em mosaicos de manchas isoladas em virtude da expansão da população humana, dando origem a um processo de fragmentação antrópica (Klink e Machado 2005). Ainda assim, apenas uma porção correspondente a 2,2\% de sua área é protegida por unidades federais de conservação, como são os casos do Parque Nacional da Chapada dos Veadeiros e do Parque Nacional das Emas no estado de Goiás (Machado 2004).

A ocupação do Cerrado teve início na década de 1920, no auge da atividade industrial, no estado de São Paulo (Klink e Machado 2005). Muito posteriormente, nas décadas de 1960-1970, com 
o esgotamento de terras férteis do sul e sudeste do Brasil e com o crescimento populacional, ocorreu a ocupação do estado de Goiás, por meio do fornecimento de subsídios e assistência técnica por parte do governo aos pecuaristas interessados (Klink e Machado 2005).

Com a construção de Brasília e a expansão das vias rodoviárias e da urbanização, a partir de 1960, o Cerrado sofreu fortes alterações. Grandes áreas foram transformadas em pastagens para a pecuária extensivas (MMA 2003, Ratter et al. 1997). Durante as décadas de 1970 e 80, o Brasil expandiu suas fronteiras agrícolas em direção ao centro- norte, resultando na modificação abrupta de $67 \%$ da área do Cerrado (Arruda 1999). Com o passar dos anos, as pastagens cultivadas e as culturas agrícolas passaram a ocupar 26,5 e 10,5\% do Cerrado, respectivamente. No ano de 2001 foi observado que $17,8 \%$ da área do Cerrado era coberta por soja plantada. Até os dias atuais existe uma forte tendência de a soja se expandir nas áreas de Cerrado, provavelmente devido ao relevo ser plano e pela fácil correção química do solo, além da alta rentabilidade deste cultivo (Anderson et al. 2003) A incorporação agrícola do Cerrado vem se mantendo em ritmo acelerado desde então (Rezende 2002, Sano et al. 2008).

Denomina-se como "uso da terra" o manejo de solo, ativo ou passivo, para o benefício do homem (Haines-Young 2009). Segundo Dias (1994). O impacto ambiental gerado pela ocupação humana no Cerrado variou de acordo com o tipo de uso da terra,

junto com a densidade populacional. No Distrito Federal o uso da terra é marcado pelo estabelecimento de zonas rurais e, posteriormente, da ocupação urbana (IBGE 2004). A ocupação dada pela urbanização na região gerou impactos ambientais específicos, como a construção de estradas, corte de morro, drenagem, desmatamento para obtenção de lenha, construção de barragens, poluição da água, atropelamento de animais, descaracterização da paisagem, substituição da biota nativa por plantas e animais exóticos (Dias 1994).

O impacto gerado pelo uso da terra para agropecuária é considerado o mais importante fator de alteração da paisagem e degradação ambiental dentro da região do Cerrado (Dias 1994). Dentre estes impactos está o aumento da frequência de queimadas, aumento da heterogeneidade de habitas pela abertura de roças, alteração na estrutura da vegetação, tornando-a mais aberta (Eitein 1972, Posey 1984). A área correspondente a atividades agropecuárias no Centro-Oeste aumentou entre 19501980 , de $25 \%$ da ocupação para 70,7\%. Da mesma forma a área cultivada (lavouras, pastos e florestamentos) passou de menos de 0,3\% em 1950 para mais de 24\% em 1985 (IBGE 1988, 1990).

No Distrito Federal, aproximadamente um terço de cobertura vegetal é ainda preservada (MMA 2003). Estas áreas são protegidas por lei, como são os casos do Parque Nacional de Brasília (30.000 hectares), a Reserva Ecológica de Águas Emendadas ( 8.000 hectares) e a reserva ecológica do Jardim Botânico (Sano 2007). As outras áreas naturais correspondem a regiões impróprias para agricultura (MMA 2003). Em relação à urbanização, o DF destaca-se por contribuir grandemente com manchas urbanas e condomínios rurais mais recentes (MMA 2003). Na porção oeste do DF concentra- 
se plantio de alimentos, predominantemente, soja, milho, feijão, hortaliças, algodão, café e cana-deaçúcar (MMA 2003).

No bioma Cerrado o processo de fragmentação está associado ás mudanças no uso da terra (Klink e Machado 2005). O processo de transformação do uso da terra nessa região tem produzido um fenômeno de perda drástica de algumas características do meio ambiente natural (Nóbrega e Encinas 2006). A modificação ambiental trazida pela urbanização e agricultura no Cerrado é extensa e resulta na fragmentação da paisagem, perda de biodiversidade, invasão biológica, a erosão do solo, poluição da água, mudanças na o regime de fogo, degradação do solo e uso intensivo de produtos químicos (MMA 2003, IBGE 2004).

Uma das principais consequências da fragmentação é a diminuição do fluxo gênico e da recolonização de áreas não habitadas pelas populações (Fahring 2003). Assim, o funcionamento do ecossistema e as populações residentes são comprometidos, transformando as comunidades naturais em manchas de comunidades dissimilares em termos de estrutura e composição (Forman e Godran 1981, Sala et al. 2000). Essas interrupções são capazes de alterar a dinâmica ecossistêmica (Viana 1990).

A rápida e severa modificação da paisagem tem ameaçado muitas espécies que por sua vez tem afetado as comunidades biológicas locais e os serviços ecológicos que elas fornecem ao ecossistema incluindo polinização, dispersão de sementes e predação de insetos. Segundo Fleming e Sosa (1994), a perda global de diversidade de mamíferos frugívoros e nectarívoros, provavelmente reflete a distribuição das manchas, em tempo e espaço, de fruta, pólen e néctar, e leva a perda de biomassa destes recursos alimentares, já que estes animais têm importante papel no sucesso reprodutivo das plantas.

Segundo, Meyer e Kalko (2008), a qualidade e permeabilidade da matriz adjacente ao fragmento de habitat, juntamente com as características ecológicas de cada espécie, são essenciais para a determinação da conectividade funcional entre o habitat remanescente e a persistência de uma espécie na paisagem fragmentada. Tem sido sugerido que a tolerância das espécies às consequências trazidas pela fragmentação pode estar relacionada com a capacidade dos organismos em atravessar áreas abertas para chegar a outros fragmentos florestais ou outros tipos de vegetação (Law et al. 1999, Schulze et al. 2000). Dessa forma, a resposta á fragmentação se difere entre os taxóns (Fahrig 2003).

Trabalhos com morcegos, relacionados á fragmentação da paisagem vem sendo realizados no bioma Cerrado (Pedro et al. 1995, Pedro et al. 2001, Bianconi 2009, Zortéa e Alho 2008, Ferreira et al. 2010, Cunha et al. 2011, Sousa et al. 2013, Pina et al. 2013, Aguiar et al. 2014, Muylaert et al. 2014, Shapiro e Bordignon 2014, Loureiro e Gregorin 2015). Estes estudos revelam que ainda não há ainda um padrão nas respostas dos morcegos á fragmentação de habitat. 


\section{Morcegos}

A maioria dos mamíferos habita ambientes terrestres, porém os morcegos passaram por uma transição extraordinária durante a sua história evolutiva, ocupando com sucesso o estrato aéreo (Gunnell e Simmons 2005, Thewissen e Babcock 1992). As

asas permitiram o sucesso dos morcegos em realizar um voo motorizado (Norberg e Rayner 1987). Outro aspecto dos morcegos que se destaca é a ecolocalização. Esse modo ativo de orientação pelo processamento dos próprios ecos dos sons que emitem fornecem além da orientação espacial a deteç̧ão, classificação e localização de presas.

Recente revisão filogenética agrupou os morcegos em Yangochiroptera e Yinochiroptera (Teeling et al. 2005). A principal característica dos primeiros é possuir pré-maxilar móvel ou ausente (os ossos na frente da mandíbula superior do rolamento dos dentes incisivos). Esta é uma característica ausente em todos os outros morcegos e mamíferos, onde estas estruturas são fundidas (Teeling et al. 2005). Na região neotropical ocorrem apenas os Yangochiroptera (Jones e Teeling 2006).

A ordem Chiroptera representa na zona Neotropical entre $40-50 \%$ das espécies, influenciando fortemente a riqueza e diversidade de mamíferos da região (Fleming 1988, Kalko 1998). A família Phyllostomidae constitui o grupo de maior abundância e diversidade de espécies nesta região (Meyer e Kalko 2008). No Brasil foram documentadas nove famílias de morcegos, 68 gêneros e 178 espécies (Nogueira et al. 2014). Existem dez espécies que são endêmicas do Brasil: Micronycteris sanborni, Dryadonycteris capixaba, Lonchophylla bokermanni, Lonchophylla peracchii, Xeronycteris vieirai, Chiroderma vizottoi, Platyrrhinus recifinus, Eptesicus taddeii, Lasiurus ebenus e Myotis izecksohni (Nobrega et al. 2014).

Morcegos possuem uma série de adaptações fisiológicas, morfológicas, comportamentais e sensoriais que permitem que eles ocupem múltiplos nichos ecológicos (Denzinger e Schnitzler 2013), o que os torna o grupo de mamíferos mais especializados (Jones e Teeling 2006). Este conjunto de atributos aliado à elevada diversidade funcional e taxonômica torna os morcegos importantes na ciclagem de nutrientes e redistribuição de energia por meio da alocação do guano, além de oferecerem serviços ecossistêmicos de magnitude de consumidores primários, secundários e terciários, resultando em maior complexidade dos ecossistemas (Fleming, 1982, 1988, Kunz et al. 2011).

Os morcegos insetívoros controlam populações de insetos e outros artrópodes tais como, aranhas e escorpiões, que ocorrem tanto em ambientes naturais como em paisagens antropogênicas, contribuindo para manter a estabilidade dos sistemas (Kunz et al. 2011, Denzinger e Schnitzler 2013). Os frugívoros ajudam no processo de dispersão das sementes ao longo de diferentes ecossistemas, podendo aumentar a diversidade em várias escalas espaciais (Fleming e Sosa 1994, Kunz et al. 2011). Os 
nectarívoros, que dispersam o pólen, auxiliam na manutenção da diversidade genética da floração das plantas, participando da fenologia reprodutiva das plantas e regeneração da vegetação (Fleming e Sosa 1994, Kunz et al. 2011, Denzinger e Schnitzler 2013). Morcegos são importantes vertebrados polinizadores no Cerrado uma vez que têm papel fundamental no ciclo de espécies vegetais típicas como exemplo Caryocar brasiliensis Cambess., Bauhinia holophylla Steud., Hymenaea stigonocarpa Mart e Luehea grandiflora Mart. \& Zucc. (Bombrowiec e Oliveira 2012). Há ainda os morcegos que se alimentam de peixes, pequenos vertebrados e sangue (Denzinger e Schnitzler 2013).

Mesmo com essa importância nos processos ecossistêmicos, pouco se sabe sobre a biologia e distribuição das espécies de morcegos no Brasil (Bernard et al. 2011). Durante o século 21 o número de novas ocorrências de espécies de morcegos no Brasil chegou a 35, e aproximadamente duas novas espécies têm sido registradas por ano, nestas duas últimas décadas (Nogueira et al. 2014). No bioma do Cerrado, os morcegos constituem o maior número de espécies de mamíferos, com mais de 100 espécies, sendo quatro endêmicas: 1) Glyphonycteris behnii Peters, (1865); 2) Lonchophylla dekeyseri Taddei, Vizotto e Sazima, 1983; 3) Thyroptera devivoi Gregorin, Golçalves, Lim e Engstrom, 2006 e 4) Lonchophilla bokermanni Sazima, Vizotto e Taddei, 1978 (Aguiar e Zortéa 2008, Paglia et al. 2012).

Os morcegos são um bom modelo de táxon para avaliar as respostas das assembleias em relação á fragmentação do habitat, pois têm potencial de se moverem sobre extensas áreas de paisagens fragmentadas e possuem características ecológicas específicas á cada espécie, o que sugere vulnerabilidade diferencial para perturbação do habitat (Norberg e Rayner 1987, Meyer e Kalko 2008, Paglia et al. 2012). Além de representarem o maior número de mamíferos do Cerrado, a habilidade de voo confere ao grupo ampla distribuição geográfica, mesmo em paisagens urbanas e rurais (Norberg e Rayner 1987).

Sabe-se que recurso alimentar e abrigo são fatores limitantes para morcegos (Fleming 1982, Kunz 1982). Assim, a resposta destes organismos à fragmentação de hábitat pode variar também de acordo com o requerimento de cada espécie (Debinski e Holt 2000, Bernard e Fenton 2006). Em estudos recentes foi observado que os padrões de distribuição espacial e disponibilidade dos recursos da matriz adjacente, que são modificados pela fragmentação, influenciam os padrões de forrageio e uso do habitat pelas espécies de morcegos (Estrada e Coates-Estrada 2002). A forma como as manchas estão distribuídas na paisagem pode influenciar a dinâmica das assembleias destes

organismos (Wiens et al. 1993). Uma das principais conclusões de estudos recentes é que resposta das espécies á fragmentação é influenciada profundamente pelo tipo de matriz que envolve o habitat fragmentado (Gascon et al. 1999, Antongiovanni e Metzger 2005, Ewers e Dedham 2006). Muitos estudos focam em diferentes aspectos do processo de fragmentação para avaliar sua influencia sobre os morcegos. Com isso, observa-se grande variação na resposta das espécies à fragmentação de 
habitat (Law e Chidel 1999, Crosson et al. 1999, Schulze e Whitacre 2000, Estrada e Coates-Estrada 2001 e 2002, Aguirre et al. 2003, Gorrensen e Willig 2004, Bernard e Fenton 2006, Estrada-Villegas et al. 2010, Pavan et al. 2011, Ethier e Fahrig 2011, Farrow e Broders 2011, Rodríguez-Durán e Otero 2011, Struebig et al. 2011, Frey-Ehrenbold 2013, Reiter et al. 2013, Ripperger et al. 2013).

Várias espécies de morcegos conseguem habitar tanto áreas urbanas, como rurais, utilizando remanescentes de vegetação nativa, ou locais que ofereçam abrigos e recursos alimentares suficientes para seu estabelecimento (e.g. Bredt e Uieda 1996, Reis et al. 2002, Opréa et al. 2009). Porém, um padrão de respostas das assembleias de morcegos em relação ao ambiente que circunda o remanescente de habitat natural ainda não foi observado.

Portanto, em minha dissertação, pretendo verificar se a fragmentação do Cerrado, devido a dois tipos de uso de solo, urbanização e agricultura, afetam as assembleias de morcegos. Para isso, vou testar duas hipótese relacionadas à resposta dos morcegos à fragmentação. A primeira hipótese de trabalho é que matrizes diferentes (urbana/rural) possuem assembleia de morcegos diferentes. E a segunda hipótese é que se as assembleias são diferentes de acordo com matriz, a dieta dos morcegos também seguirá o mesmo padrão, sendo diferente entre as duas matrizes.

\section{VIVER NO CAMPO OU NA CIDADE? RESPOSTA DOS MORCEGOS (MAMMALIA, CHIROPTERA) A ANTROPIZAÇÃO DA PAISAGEM}

\section{Resumo}

O Cerrado é uma região em constante alteração antrópica para fins agropecuários e de urbanização. A fauna desse bioma deve sofrer impactos com essas alterações. Neste estudo avalio a resposta das assembleias de morcegos à urbanização e uso da terra para agricultura na cidade de Brasília, e verifico se a dieta destes organismos reflete as características das matrizes adjacentes aos fragmentos estudados. Para tanto, amostrei fragmentos de cerrado sensu stricto inseridos em matriz rural e urbana, e comparei a assembleia de morcegos em termos de diversidade e composição de espécies presente em cada uma delas. Foram analisados isótopos estáveis de carbono e nitrogênio dos pelos dos morcegos para verificar se a dieta refletia a distribuição das assembleias. Foi feito um test $t$ para comparar as diversidades dos dois tipos de ambiente e uma NMDS, seguida de um ANOSIM, para testar se havia diferença na composição de espécies. Foram capturados 310 morcegos pertencentes a três famílias e 18 espécies. Phyllostomidae foi a família com maior riqueza e Artibeus lituratus e Glossophaga soricina as espécies mais abundantes. Quatro espécies foram exclusivas da matriz rural e duas da matriz urbana. Houve diferença significativa na diversidade (t: 2.5649, df: 279.86, p: 0.010843) das assembleias de morcegos dos dois ambientes e a composição de espécies $(R=0,2579 ; p<0,014)$ foi diferente. Não foi verificada diferença significativa na composição isotópica de $\mathrm{C}$ e $\mathrm{N}$ na dieta dos morcegos das diferentes guildas alimentares entre as duas matrizes. A primeira hipótese de que existe diferença nas assembleias de morcegos entre os dois tipo de matrizes foi 
corroborada, o que sugere que o tipo de uso da terra é um fator importante a ser levado em consideração nos estudos de assembleia de morcegos. Porém a dieta destes animais não seguiu o mesmo padrão, o que refuta a segunda hipótese. Este fato é um indicativo de que os morcegos estão se alimentando de forma similar nos dois tipos de ambiente.

Palavras-chave: Chiroptera, paisagem, fragmentação, perda de habitat, mancha, matriz, dieta, hábito alimentar, isótopos estáveis

\section{Abstract}

Cerrado is a constantly changing region. Anthropogenic changes for agricultural purposes and urbanization are the main forces affecting the biome. These changes will probably impact its fauna. In this study, I evaluate the response of bats assemblages to urbanization and land use for agriculture in Brasília, and check whether the diet of these organizations reflects the characteristics of adjacent matrices to study fragments. For that, I compared the assemblages of bats located in fragments of cerrado sensu stricto inserted in rural and urban matrices. Assemblages were evaluated in terms of diversity and composition of species present in each fragment. To verify if the diet of bat assemblages reflected their distribution, I analyzed stable carbon and nitrogen isotopes from bat's fur. To compare the diversity between both kinds of environment, I conducted a $T$ test and a NMDS, then an ANOSIM to test for differences in species composition. I captured 310 bats belonging to three families and 18 species. Phyllostomidae was the family with greater richness, and Artibeus lituratus and Glossophaga soricina, the most abundant species. Four species were unique to rural matrix and two unique to urban matrix. There were significant differences in diversity (t: 2.5649, df: 279.86, $\mathrm{p}: 0.010843$ ) of bat assemblies between both kinds of environments and species composition $(R=0.2579, p<0.014)$ was also different. There was no significant difference in isotopic composition of $\mathrm{C}$ and $\mathrm{N}$ in the diet of bats of different feeding guilds between the two matrices. The first hypothesis that there is difference in the bats' assemblages between both kinds of matrices was corroborated, which suggests that the type of land use is an important factor to be taken into account in bats assemblage studies. However, the diet of these animals did not follow the same pattern, which refutes the latter hypothesis. This fact indicates that bats are feeding similarly in both types of environment.

Keywords: Chiroptera, diet, feeding habits, fragmentation, habitat loss, landscape, matrix, patch, stable isotopes

\section{Introdução}

A extinção de espécies em ambientes fragmentados é uma consequência da redução do tamanho e do isolamento da área original, que expõe as populações locais às alterações na disponibilidade de recursos e mudanças das condições ambientais (Wiens 1989, Murcia 1995). Na 
literatura, alguns autores consideram os morcegos pouco vulneráveis à fragmentação de habitat quando comparados a outros mamíferos (Estrada e Coates-Estrada 2001) por poderem se deslocar bastante para buscarem recursos e assim escapar das mudanças ambientais locais. Outros autores mostram que morcegos respondem de diversas formas às mudanças no habitat (Castro-Luna et al. 2007). Alguns estudos mostram uma diminuição na abundância e riqueza de espécies (e.g. Struebig et al. 2011, Maldonado-Coelho e Marini 2004, Faria 2006), mas a maior parte dos autores concorda que a resposta dos morcegos é espécie-específica,,e dependente do modo como cada uma utiliza abrigo, do hábito alimentar e do tipo de forrageio de cada uma (Debinski e Holt 2000, Bernard e Fenton 2006, Willig et al. 2007, Estrada-Villegas e Kalko 2010, Ferreira et al. 2010, Sousa et al. 2013).

Espera-se que na fragmentação de habitats ocorra uma redução na abundância de organismos especialistas, incapazes de usarem o habitat matriz (Laurance 1991, Debinski e Holt 2000). Assim, as novas condições produzidas pela fragmentação podem beneficiar espécies generalistas ou exóticas, fornecendo alimento, abrigo e locais para reprodução. Mas ao contrário, espécies especialistas podem ser adversamente afetadas se determinados recursos-chave são modificados ou removidos (McKinney 2006). No caso dos morcegos, por exemplo, muitas espécies conseguem habitar áreas urbanas e rurais, pois podem utilizar fragmentos de vegetação nativa, ou mesmo áreas artificiais, contanto que estas ofereçam abrigo e recursos alimentares (Sazima et al. 1994, Bredt e Uieda 1996, Reis et al. 2002, Lima 2008, Oprea et al. 2009).

Mudanças na abundância das espécies de morcegos podem ser observadas dependendo da disponibilidade de recursos alimentares e de abrigo na matriz que circunda seu habitat (Alvarez e Gonzilez-Quintero 1970, Stoner 2005). Avaliações que descrevem a estrutura da matriz onde o fragmento está inserido e a interação dos organismos com este componente espacial (e.g. Fahring e Merrian 1994, Ewers e Didham 2006) podem ser adequadas para determinar os efeitos da fragmentação sobre os morcegos (Gorresen e Willig 2004, Meyer e Kalko 2008, Klingbeil e Willig 2009), particularmente sobre sua dieta.

A análise de isótopos estáveis de carbono $\left(\delta^{13} \mathrm{C}\right)$ e nitrogênio $\left(\delta^{15 N}\right)$ em estudo das relações tróficas em comunidades vem sendo usada para elucidar melhor a ecologia alimentar de morcegos (Hobson et al. 2000, Rex et al. 2010, 2011, Voigt 2010, Dammhahn e Goodman 2014). Estes elementos, carbono e nitrogênio, possuem um tempo de vida relativamente alto dentro dos organismos e revelam informações distintas (Voigt et al. 2003, Voigt e Matt 2004). Geralmente, valores de $\delta^{13} \mathrm{C}$ refletem fontes de carbono da dieta dos animais, já que estes não alteram substancialmente a composição isotópica de sua alimentação (Tieszen et al. 1983). Enquanto que valores de $\delta 15 \mathrm{~N}$ são enriquecidos ao longo do consumo alimentar de um organismo de forma previsível, o que indica sua posição dentro da rede trófica (DeMots et al. 2010). Desta forma, a avaliação da dieta dos morcegos 
por meio de isótopos estáveis é uma maneira de testar a validade de dados alimentares em uma escala mais refinada.

A matriz da paisagem estudada pode influenciar a abundância de morcegos (Avila-Cabadilla et al. 2009). Estudos que levam em consideração o efeito do processo de fragmentação sobre os morcegos são importantes, pois uma vez que o estresse ambiental gerado pelo processo de fragmentação afeta a estrutura das assembleias de morcegos, a dinâmica e regeneração do ecossistema também serão comprometidos, já que estes organismos possuem alta variedade de grupos funcionais, que contribuem para manutenção da estabilidade do sistema (Fleming, 1988, Cosson e Masson 1999, Kunz et al. 2011).

A fragmentação de hábitat já provocou a perda de $66 \%$ da cobertura original do Cerrado (Hoffmann e Jackson 2000, Machado et al. 2004), considerado uma das 35 áreas mais ameaçadas do mundo (Redford e Fonseca 1986, Myers et al. 2000, Ratter et al. 2003, Mittermeier et al. 2005). Nas últimas décadas, a população humana da região Centro-Oeste cresceu seis vezes, com $80 \%$ das pessoas vivendo em áreas urbanas (Bezerra e Júnior 2004, Dias 2008). A urbanização trouxe grandes impactos, como a expansão do desmatamento para obtenção de recursos, a expansão do tráfego de veículos e consequente atropelamento de fauna, e a descaracterização da paisagem e da biota nativa (Dias 2008). Esses processos resultaram em graves consequências para o Cerrado, tais como, alteração da produtividade e diversidade animal e vegetal, alteração no padrão de herbivoria e ciclagem de nutrientes, bem como fragmentação da cobertura vegetal (Dias 2008). Desta forma, até 2008, as duas classes de uso da terra mais comuns eram as pastagens cultivadas e as culturas agrícolas, ocupando 26,5 e 10,5\% do Cerrado, respectivamente. Enquanto 889 mil hectares eram ocupados por áreas urbanas e 7.870 hectares de área com mineração (Sano et al. 2008).

No Distrito Federal, aproximadamente um terço de cobertura vegetal é ainda preservada (MMA 2003). Estas áreas são protegidas por lei, como são os casos do Parque Nacional de Brasília (30.000 hectares), a Estação Ecológica de Águas Emendadas ( 8.000 hectares) e a reserva ecológica do Jardim Botânico (Sano 2007). As outras áreas naturais correspondem a regiões impróprias para agricultura (MMA 2003). Em relação à urbanização, o DF destaca-se por contribuir grandemente com manchas urbanas e condomínios rurais mais recentes (MMA 2003). Na porção oeste do DF concentrase plantio de alimentos, predominantemente, soja, milho, feijão, hortaliças, algodão, café e cana-deaçúcar (MMA 2003).

Assim, testei se as assembleias de morcegos de Brasília diferem-se quanto a composição, riqueza e diversidade entre matrizes (i.e. urbana e rural). Com base nisto, testei também se a dieta dos morcegos refletiu esta diferença, em relação aos valores de isótopos estáveis de carbono $\left(\delta^{13} \mathrm{C}\right)$ e nitrogênio $(\delta 15 N)$ na dieta, já que espero encontrar uma dieta mais nativa $(C 3)$ nas áreas rurais, onde há maior número de área nativa remanescente, que nas áreas urbanas. Para isto, os morcegos foram 
divididos em guildas alimentares amplas: animalívoros e fitófagos. Em seguida foram classificados em guildas alimentares mais específicas (frugívoro, nectarívoros, insetívoros e onívoros).

\section{Métodos}

Área de estudo

O cerrado sensu stricto no estado do Distrito Federal - DF é a fitofisionomia mais atingida pela modificação do uso da terra (Klink e Moreira 2002, Klink e Machado 2005). Durante os meses de fevereiro e agosto de 2014, amostrei morcegos em remanescentes de cerrado s.s. inseridos em áreas de matriz rural e matriz urbana no Distrito Federal. Selecionei primariamente por imagem de satélite oito fragmentos, com base na presença de vegetação tipicamente nativa. Após essa seleção verifiquei se cada fragmento possuía cerrado s.s. e se mantinham uma distância mínima de 3,5 km de distancia entre eles, para evitar a sobreposição de assembleias, já que espécies pequenas que ocorrem no Cerrado percorrem frequentemente distâncias de 2 a 3,5 km (Aguiar et al. 2014).

O clima da região de estudo é tipicamente estacional, e de acordo com a classificação de Köppen Aw, classificado como tropical sazonal. Tem precipitação

média de 800-2000 mm (Brazil 1984), sendo que as chuvas se concentram de outubro a março, e a seca ocorre nos períodos de abril a setembro (Dias 1992). As temperaturas médias anuais registradas para o Cerrado estão em torno de 18-28 C (Brazil 1984, Dias 1992, Clein 2002). Muitas espécies vegetais que são comuns e amplamente distribuídas no Cerrado s.s. são utilizadas por morcegos desta região, como Caryocar brasiliensis; Bauhinia spp.; Hymenaea stigonocarpa; Dipteryx alata; Pseudobombax spp. (Bredt et al. 1996).

\section{Caracterização dos fragmentos e das matrizes}

As matrizes foram caracterizadas a partir da sobreposição de um mapa das áreas remanescentes (fragmentos) com um mapa do uso da terra do Distrito Federal, obtido no departamento de Engenharia Florestal da Universidade de Brasília (Carvalho 2015, com. pes.). O mapa de uso da terra continha as variáveis que categorizavam o tipo de uso de solo do Distrito Federal, tendo por base classificação visual de imagens do Landsat.

Assim, foram consideradas urbanas as seguintes características: área urbana com/sem infraestrutura; ferrovia e metrô; estradas pavimentadas; área em processo de parcelamento; área verde intra-urbana. Enquanto as características rurais consideradas foram: avicultura; chácara de uso misto; cultura de grãos; estradas não pavimentadas; olericultura; pastagem e mineração. Após a sobreposição dos mapas foi gerado um buffer de raio de $3.5 \mathrm{~km}$, tomado a partir da borda de cada fragmento, para a caracterização da matriz. A área de cada categoria de uso de solo foi estimada e posteriormente transformada em porcentagem. Porém as categorias referentes à vegetação presente no buffer foram desconsideradas, já que eram características presentes em todos os fragmentos 
estudadas e não contribuíam para distinção das matrizes. Como também, as características de uso do solo que representaram menos de $5 \%$ em cada buffer foram compiladas na categoria "outros".

A paisagem que circunda cada fragmento foi definida como urbana ou rural de acordo com a porcentagem de cada característica do uso do solo que circunda cada fragmento. As áreas que continham mais de $50 \%$ de características rurais foram consideradas como contendo uma matriz rural. Enquanto que as áreas que continham mais de 50\% de características urbanas foram classificadas como fragmentos de matriz urbana (Figura 1). Foi realizada também uma análise de Cluster para verificar a separação dos fragmentos em grupos distintos. A análise se Cluster mostrou uma

separação dos pontos de coleta em dois grupos gerais (Figura 2). No primeiro agruparam-se três fragmentos a considerados de matriz urbana, pois possuem maior porcentagem de características urbanas na paisagem circundante, são eles: U1 (1545’57.24”S, $\left.\quad 47^{\circ} 51^{\prime} 19.76^{\prime \prime} \mathrm{W}\right)$; $\quad$ U2 (155' $16.87^{\prime \prime}$ S, $\quad 47^{\circ} 56^{\prime} 39.12$ 'W); U3

(1547'56.87"S, 4759'36.16”W). Todas as áreas amostradas estão nos limites da cidade de Brasília, rodeadas por intenso trânsito de veículos e estabelecimentos residenciais e/ou comerciais sob constante pressão urbana. No segundo grupo estão os fragmentos inseridos em matriz com características mais rurais. Neste grupo foram amostrados cinco fragmentos: R1 (1540'19.24"S,

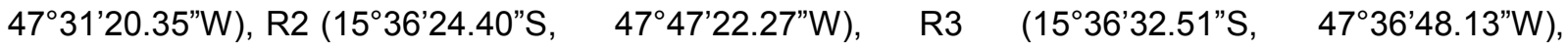
R4

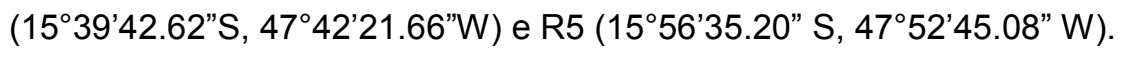

Os pontos desta região estão agrupados na Bacia do São Bartolomeu. Apesar de conter 39\% das áreas de proteção inseridas no DF, essa bacia vem sofrendo intenso processo de ocupação humana, englobando também boa parte das áreas consideradas urbanas do DF (UNESCO 2003). Nesta região ocorrem propriedades particulares, predominantemente chácaras, sítios e fazendas (Machado et al. 1997). Estes pontos estão circundados em grande parte por fazendas, pastos, áreas de agricultura, pomares, criação de animais domésticos e áreas desmatadas para loteamento.

Para confirmar se os fragmentos estudados eram rodeados principalmente por características urbanas ou rurais foram construídos gráficos representando a porcentagem de cada tipo de uso de solo das matrizes. Assim, os fragmentos com porcentagem de atividades rurais acima de $50 \%$ foram inseridos no grupo de matriz rural, enquanto os que possuem mais de $50 \%$ de área urbana formaram o grupo de matriz urbana.

$$
\begin{array}{r}
100 \% \\
90 \% \\
80 \% \\
70 \% \\
60 \%
\end{array}
$$


$\begin{array}{llllllll}\mathrm{R} 1 & \mathrm{R} 2 & \mathrm{R} 3 & \mathrm{R} 4 & \mathrm{R} 5 & \mathrm{U} 1 & \mathrm{U} 2 & \mathrm{U} 3\end{array}$

Área urbana Outros

Atividade agrícola

Figura 1. Porcentagem das características de uso do solo da matriz circundante aos oito remanescentes de cerrado sensu stricto do Distrito Federal, em um buffer de raio de $3.5 \mathrm{~km}$, tomado a partir da borda de cada fragmento. 


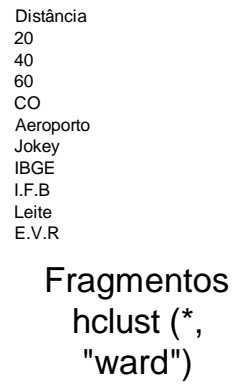

Figura 2. Dendrograma de similaridade entre os tipos de uso de solo das matrizes adjacentes aos oito fragmentos de Cerrado sentido restrito no Distrito Federal. Os fragmentos inseridos em matriz urbana são: CO (U1), Aeroporto (U2), Jockey (U3) e os fragmentos inseridos em matriz rural são: Juliano (R1), IBGE (R2), I.F.B (R3), Leite (R4) e E.V.R (R5).

\section{Amostragem de morcegos e variáveis das assembleias}

As amostragens de morcegos foram realizadas durante seis expedições com intervalos de 30 dias entre elas. Em cada ponto foram utilizadas 15 redes de neblina (12

x 2,5m) mantidas abertas durante cinco horas. As redes foram checadas em intervalo de $20 \mathrm{~min}$. $\mathrm{O}$ esforço amostral foi realizado conforme Straube e Bianconi (2002), esforço amostral = área da rede $(450 \mathrm{~m}) \times$ tempo de exposição $(5 \mathrm{~h}) \times$ número de repetições $(48)$ x número total de redes $(120)=$ 12.960.000 h.m². Todos os morcegos capturados foram retirados da rede e medidos (antebraço; orelha; tarso; cabeça-corpo; cauda), para auxílio na identificação das espécies. Após as medidas os morcegos eram anilhados com anilhas plásticas numeradas e soltos. Os morcegos foram identificados por meio de chaves de identificação (Vizotto e Taddei 1973, Lim e Engstrom 2001, Gardner 2007, Dias et al. 2011, Reis et al. 2013). Cada espécie teve um macho e uma fêmea coletados como material testemunho e estão depositados na Coleção do Laboratório de Morcegos da Universidade de Brasília.

Para verificar se o esforço amostral foi suficiente para estimar a riqueza de espécies foi feita uma curva de rarefação. Este método estatístico estima o número de espécies que pode ser esperado em uma amostra $\mathrm{n}$ de indivíduos, elaborados a partir de uma população de indivíduos de $\mathrm{N}$ totais distribuídos entre as espécies. O índice de diversidade de espécies utilizado foi índice de ShannonWeaver, calculado para cada ponto de estudo, calculada a partir da fórmula:

$H^{\prime}=-\sum S i=1$ pi In pi, onde pi: freqüência de cada espécie, para i variando de 1 a $S$ (Riqueza). 
O índice de Simpson também foi analisado, a título de comparação, calculado pela fórmula:

$\lambda=\Sigma S 1 \mathrm{p}$ i2, onde pi é a proporção de cada espécie, para i variando de 1 a $S$ (Riqueza), e pi é frequência da espécie $\mathrm{i}$.

A abundância de espécies foi determinada pela contagem simples do número de indivíduos capturados em cada ponto de coleta. A partir dos dados de abundância total das espécies de cada fragmento foi feita uma análise de ordenação com base no índice de Bray-Curtis (Bray e Curtis 1957), através do método de Escalonamento Multidimensional Não-Métrico (NMDS, na sigla original em inglês), para evidenciar padrões de similaridade em composição de espécies entre as áreas, que estavam classificadas em urbana ou rural. Essa similaridade foi testada com uma Análise de Similaridade (ANOSIM). Para verificar se as assembleias dos ambientes rurais diferiam das dos ambientes urbanos em relação à diversidade de espécies foi realizada um Test $t$ para cada índice de diversidade (Shannon/Simpson). Foi realizada também uma análise

de correlação espacial, a PCNM, para verificar se havia alguma dependência espacial entre os pontos de coleta.

Os morcegos foram classificados nas seguintes guildas alimentares: frugívoros; nectarívoros; insetívoros; hematófago e onívoros. Cada guilda foi representada por três espécies com quantidades aleatórias de indivíduos. Também foi feita uma classificação mais ampla, a título de comparação. Assim os morcegos foram divididos em animalívoros e fitófagos.

\section{Dados de dieta}

Uma vez que pelo é um tecido metabolicamente inerte e mantem a razão isotópica da dieta mais atual (Voigt et al 2003), foram coletados pelos da região dorsal de cada morcego capturado para análise isotópica da dieta. O procedimento de preparo do pelo para envio para análise foi o mesmo adotado por Salgado et al. (2014). As composições isotópicas das amostras foram comparadas com os padrões internacionais (PDB). Relações isotópicas são expressas pela notação $\delta$ em partes por mil $(\%)$, utilizando a seguinte equação para isótopos de carbono:

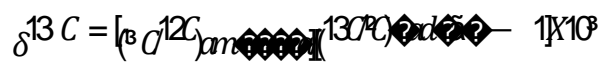

e de isótopos de nitrogênio:

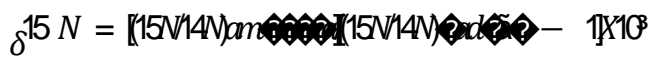

As análises de $\mathrm{C}$ fornecem dados a respeito da origem do recurso alimentar de cada morcego, e essas podem ser origem alimentar C3 ou C4. As espécies de plantas do tipo C3 (árvores) possuem valores de $\delta 13 \mathrm{C}$ que variam entre $-20 \%$ e $-32 \%$, com média de $-27 \%$, enquanto que os valores de $\delta^{13} \mathrm{C}$ das espécies C4 (gramíneas) variam entre - 9\%o e -17\%, com média de $-13 \%$. Assim, plantas C3 e C4 possuem valores de $\delta^{13} \mathrm{C}$ que diferem de aproximadamente $14 \%$ entre si (Boutton 1996). As análises de $\mathrm{N}$ mostram o nível trófico que cada indivíduo ocupa em determinado sistema e pode 
confirmar se um animal incluso em determinada guilda alimentar, está se alimentando mesmo de elementos que compõe sua dieta base. A maioria $\delta 15 \mathrm{~N}$ foliar de plantas do Cerrado varia de $-2,5 \%$ para 4,5 \%o (Bustamante et al. 2004, Coletta et al. 2009).

Para verificar se há diferença na origem alimentar e nível trófico de morcegos que vivem em matriz urbana e rural foram construídos Boxplots e gráficos de dispersão dos morcegos separados pelo tipo de ambiente em que habitam, plotados com seus respectivos valores de composição isotópica de carbono e nitrogênio. Posteriormente verificou-se se essa diferença estava sendo refletida nas guildas alimentares, que foram

separadas por tipo de ambiente com seus respectivos valores de composição isotópica de carbono e nitrogênio. Isso foi realizado para cada guilda alimentar separadamente e com todas sendo plotadas juntas em um só Boxplot.

\section{Resultados}

Diferença entre as Matrizes

As matrizes de habitat caracterizadas a partir do tipo de uso do solo demostraram que os fragmentos possuem características da paisagem circundantes distintas, que separam os fragmentos em dois grupos de acordo com as porcentagens de cada característica (Figura 1). De acordo com estas porcentagens, três fragmentos são circundados por matriz urbana e cinco por matriz rural. A análise de cluster confirmou esta separação dos fragmentos em dois grupos distintos (Figura 2).

O resultado da PCMN indicou que não há nenhum tipo de dependência espacial entre os fragmentos estudados, mostrando que a distância entre os fragmentos não exerce influencia sobre a ocorrência das espécies.

\section{Assembleia de morcegos}

Entre as comunidades de morcego analisadas foram capturados, no total, 310 indivíduos distribuídos em três famílias: Phyllostomidae, Molossidae e Vespertilionidae, e 18 espécies. A família Phyllostomidae foi a que teve maior riqueza, sendo capturadas 15 espécies de morcegos de cinco subfamílias (Desmodontinae, Glossophaginae,

$$
\text { Phyllostominae, Carolliinae e Stenodermatinae), seguida de }
$$

Molossidae com três espécies e Vespertilionidae, com apenas uma espécie (Tabela 1). Os fragmentos de matriz rural contribuíram mais para a riqueza e abundância de espécies geral, com 16 espécies e 170 indivíduos. Enquanto que nos fragmentos de matriz urbana foram capturados 140 indivíduos e 14 espécies. (Tabela 1 e 2, e Figura 3). Em relação à abundância de indivíduos, no geral, a espécie mais abundante foi Artibeus lituratus, contribuindo com 111 indivíduos. A segunda espécie mais abundante foi Glossophaga soricina, com 42 indivíduos. Houve espécies que tiveram 
apenas uma ocorrência (Anoura geoffroyi; Glyphonycteris behnii; Chiroderma doriae; Chiroderma villosum) (Tabela 1). Algumas espécies mostraram diferença significativa em relação á abundância entre os dois tipos de matriz. São elas: Dermanura sp., Artibeus planirostris, Carollia perspicillata,

Platyrrhinus lineatus, Sturnira lilium e Desmodus rotundus (Tabela 1).

As diferentes matrizes, urbana e rural, apresentam assembleias de morcegos diferentes em termos de composição e diversidade de espécies. Em relação ao índice de diversidade de Shannon, os valores foram H': 2.1787 e H': 1.8704, para matriz rural e urbana respectivamente. Enquanto o índice de Simpson foi D: 0.15903 e D: 0.23306, para matriz rural e urbana respectivamente. $O$ resultado da Test $t$ mostrou que há diferença significativa entre as diversidades dos morcegos entre as matrizes urbana e rural (Shannon= t: 2.5649, df: 279.86, p: 0.010843 /Simpson= t: -2.2991 , df: 241.43, p:

0.022353).

A NMDS mostrou claramente associações de determinadas espécies com o ambiente. Assim, a dissimilaridade entre a matriz urbana e a matriz rural em termos de composição de espécies foi confirmada estatisticamente pelo teste ANOSIM ( $R=0,2579 ; p<0,014)$. Algumas espécies estiveram presentes somente em fragmentos de matriz rural. Estas foram, por exemplo, L. dekeyseri, G. behnii, C. doriae e C. villosum. Vale ressaltar a ocorrência das espécies Desmodus rotundus, Artibeus planirostris e Platyrrhinus lineatus, que apesar de não terem sido registradas exclusivamente em fragmentos rurais, foram representadas por poucos indivíduos em fragmentos urbanos. A abundância de $D$. rotundus foi de 12 indivíduos em matriz rural, para um indivíduo em matriz urbana. A espécie $A$. planirrostris teve 16 ocorrências em matriz rural e uma em urbana. E a espécie $P$. lineatus, que ocorreu 27 vezes em matriz rural e seis em ambiente urbano (Tabela 1).

Da mesma forma, as espécies $A$. geoffroyi e Cynomops planirostris ocorreram exclusivamente em fragmentos de matriz urbana. Outro caso a se destacar é o da espécie Sturnira lilium, que apesar de ter ocorrido nos dois tipos de matriz, teve uma maior abundância em fragmentos urbanos, com 22 indivíduos, enquanto que em fragmentos rurais foram capturados apenas quatro indivíduos (Tabela 1). Dessa forma, em relação à composição de espécies nos diferentes tipos de matriz, temos duas espécies exclusivas de matriz urbana e quatro exclusivas de ambiente rural, porém as abundâncias destas espécies foram baixas. (Tabela 1).

No geral as curvas de rarefação mostraram que não houve completa estabilização da riqueza de espécies, já que nos dois tipos de matriz não foi alcançada uma assíntota. Isto revela que ainda podem ser encontradas novas espécies de morcego nestes locais, ao se aumentar o esforço amostral. As assembleias de morcegos da matriz rural apresentam uma riqueza de espécies um pouco maior que as assembleias de morcegos 
da matriz urbana, porém esta diferença não parece ser expressiva, já que os intervalos de confiança das curvas se sobrepõem (Figura 3).

Tabela 1. Distribuição da abundância das espécies de morcegos em fragmentos de Cerrado inseridos em matriz urbana e rural no Distrito Federal. Os morcegos foram divididos em guildas alimentares e separados por família.

\begin{tabular}{|c|c|c|}
\hline $\begin{array}{l}\text { Guilda alimentar } \\
\text { Família } \\
\text { Espécie }\end{array}$ & Matriz Rural & Matriz Urbana \\
\hline \multicolumn{3}{|l|}{ Frugívoros } \\
\hline \multicolumn{3}{|l|}{ Phyllostomidae } \\
\hline Artibeus lituratus & 53 & 58 \\
\hline Dermanura sp. & 9 & 1 \\
\hline Artibeus planirrostris & 16 & 1 \\
\hline Carollia perspicillata & 12 & 4 \\
\hline Chiroderma doriae & 1 & 0 \\
\hline Chiroderma villosum & 1 & 0 \\
\hline Platyrrhinus lineatus & 27 & 6 \\
\hline Sturnira lilium & 4 & 22 \\
\hline \multicolumn{3}{|l|}{ Nectarívoros } \\
\hline \multicolumn{3}{|l|}{ Phyllostomidae } \\
\hline Anoura geoffroyi & 0 & 1 \\
\hline Glossophaga soricina & 19 & 23 \\
\hline Lonchophylla dekeyseri & 4 & 0 \\
\hline \multicolumn{3}{|l|}{ Insetívoros } \\
\hline \multicolumn{3}{|l|}{ Molossidae } \\
\hline Cynomops planirostris & 0 & 3 \\
\hline Molossops temminckii & 4 & 9 \\
\hline \multicolumn{3}{|l|}{ Vespertilionidae } \\
\hline Eptesicus diminutus & 1 & 5 \\
\hline \multicolumn{3}{|l|}{ Hematófagos } \\
\hline \multicolumn{3}{|l|}{ Phyllostomidae } \\
\hline Desmodus rotundus & 12 & 1 \\
\hline \multicolumn{3}{|l|}{ Onívoros } \\
\hline \multicolumn{3}{|l|}{ Phyllostomidae } \\
\hline Glyphonycteris behnii & 1 & 0 \\
\hline Phyllostomus discolor & 4 & 2 \\
\hline Phyllostomus hastatus & 2 & 4 \\
\hline Total & 170 & 140 \\
\hline
\end{tabular}


14

Riqueza (95\% de confiança)

12

10

8

6

4

2

0

20

40

60

80

100

120

140

160

180

n

d

i

v

í

u

0

$\mathrm{S}$

Figura 3. Curva de rarefação de espécies de morcegos dos fragmentos para matrizes urbana e rural em fragmentos de cerrado sensu stricto no Distrito FederalDF. 


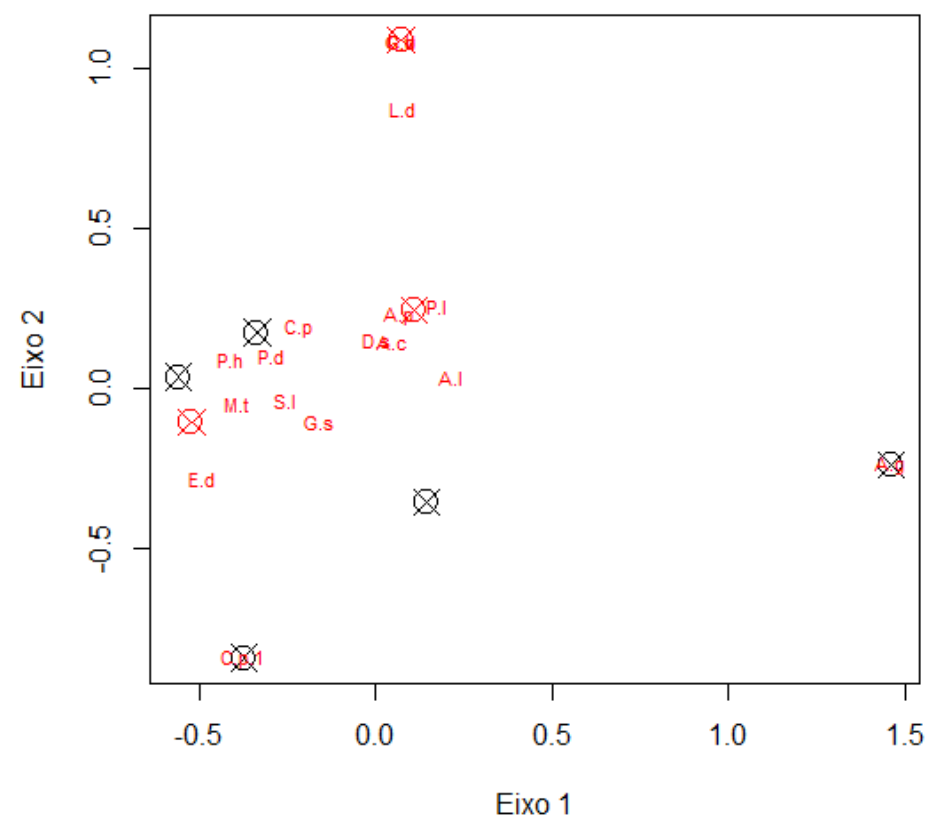

Figura 4. Escalonamento multi-dimensional não métrico (NMDS) das composições das espécies de morcegos em cinco fragmentos de matriz rural (círculos pretos) e três fragmentos de matriz urbana (círculos vermelhos). As diferentes siglas são as espécies (S.I=Sturnira lilium, M.t = Molossops temninckii, P.h=Phyllostomus hastatus,

G.s=Glossophaga soricina, A.I=Artibeus lituratus, E.d=Eptesicus cf. diminutus, P.I= Platyrrhinus lineatus, C. $\mathrm{p}=$ Carollia perspicillata, L. $\mathrm{d}=$ Lonchophylla dekeyseri, A.p $=$ Artibeus planirrostris, G.b=Glyphonycteris behnii A.c= Desmanura sp., P.d= Phyllostomus discolor, A.g= D.s= Desmodus rotundus, C.v=Chiroderma villosum, C.p1= Cynomops planirrostris, C.d= Chiroderma doriae).

Dieta

Em termos isotópicos, não houve diferença na dieta dos morcegos entre os dois tipos de matrizes. Quando se observa os dados em nível de guildas alimentares (frugívoro, onívoro, insetívoro, nectarívoro) verifica-se que não há diferença em relação à fonte alimentar das espécies e nem de seus níveis tróficos entre os dois tipos de matrizes (Figuras 5). Para as categorias mais amplas de animalívoros e fitófagos (Figuras 6), também não há diferença. 

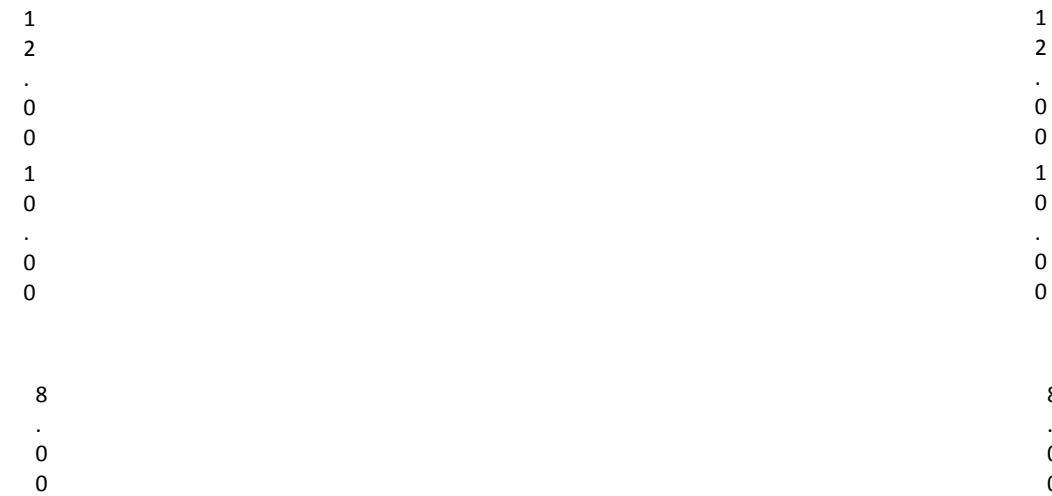

8

0

$\begin{array}{ll}4 & \\ . & \\ 0 & \\ 0 & \\ 2 & \\ . & \\ 0 & \\ 0 & \\ 0 & \\ . & \\ 0 & \\ 0 & \\ & \\ & - \\ & 3 \\ & 0 \\ & \\ & 0 \\ & 0 \\ & \end{array}$

A

4

0

0

5
5
0
0

2

0

0

$-15.00$

2
0
0
0

2
5
.
0
0

2
3
0
0

0

1

0

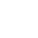

1

.

0
0

-

7

0

6.00

6.00 
12.00

10.00

$\delta 15 \mathrm{~N}$

8.00

6.00

4.00

2.00

0.00

12.00

10.00

8.00

6.00

4.00

2.00

0.00

\section{Rural}

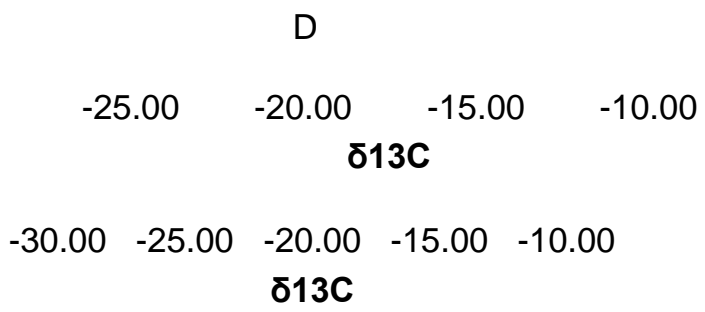

Figura 5. Valores de $\delta^{13 C}$ e ao $\delta 15 \mathrm{~N}$ das guildas de morcegos em ambiente urbano e ambiente rural para morcegos frugívoros $(A)$, nectarívoros (B), insetívoros (C), e onívoros (D). 
Figura 6. Boxplot dos morcegos fitófagos em relação á fonte alimentar ( $\left.\delta^{13 C}\right)$ (gráfico "a") e ao nível trófico $\delta 15 \mathrm{~N}$ (gráfico "b"), em remanescentes de Cerrado inseridos em matriz urbana e rural do Distrito Federal.

Figura 7. Boxplot dos morcegos animalívoros em relação á fonte alimentar ( $\left.\delta^{13 C}\right)$ (gráfico "a") e ao nível trófico $\delta 15 \mathrm{~N}$ (gráfico "b") em remanescentes de Cerrado inseridos em matriz urbana e rural do Distrito Federal.

Desta forma há um padrão geral dos hábitos alimentares dos morcegos de matriz rural e urbana, observados de forma unificada. Morcegos animalívoros mantiveram os valores de $\delta^{13 \mathrm{C} \text { mais }}$ próximos á fontes alimentares C4, que os morcegos fitófagos (Figura 9). No entanto, ocorreram exceções para três indivíduos da espécie Phyllostomus discolor, um indivíduo da espécie Phyllostomus hastatus, um Eptesicus diminutus, um Desmodus rotundus e o único Glyphonycteris behnii que mantiveram seus valores de $\delta 13 \mathrm{C}$ mais abaixo do nível considerados de animalívoros (Figura 9). Em relação ao nível trófico observou-se que vários indivíduos classificados como fitófagos tendem a possuir valores mais baixos de $\delta 15 \mathrm{~N}$ que os animalívoros. No entanto, alguns indivíduos fitófagos conseguem alcançar valores de $\delta 15 \mathrm{~N}$ próximos aos valores que representam os morcegos animalívoros (Figura 9).

Os morcegos frugívoros e nectarívoros se diferenciam dos hematófagos em relação ás fontes alimentares (Figura 8). Os frugívoros possuem os valores mais baixos de $\delta 15 \mathrm{~N}$, enquanto os hematófagos os valores mais altos. Os morcegos onívoros possuem grande amplitude de composição isotópica de carbono, variando de -24 a -16 (Figura 8).

Quando analisamos os resultados para cada espécie (Figura 10), ao contrário do que se esperava, observa-se que nem todos os morcegos que possuem hábito frugívoro apresentaram baixa assinatura isotópica $(\delta)$ de nitrogênio $(\mathrm{N})$. As espécies Artibeus lituratus, Artibeus planirostris, Carollia perspicillata, Chiroderma vilosum e Sturnira lilium possuem estas discriminações acima de 6/1000 $\delta 15 \mathrm{~N}$. Enquanto que para estas mesmas espécies supracitadas, as discriminações isotópicas do elemento carbono (C) variaram entre -25 e -22, ou seja, os indivíduos estão utilizando-se de fontes de alimento C3, independente da matriz onde foram capturados. 
A espécie Dermanura sp. destacou-se por ser a única entre as frugívoras que apresentou baixa assinatura isotópica $(\delta)$ de $\mathrm{N}$, o que representa bem esta guilda. Além disso, Dermanura sp. possui valor de carbono $(\mathrm{C})$ dentro da faixa de valores considerados como fonte de alimento C3 (Figura 10). As espécies Glossophaga soricina e Lonchophylla dekeyseri apresentaram valores mais altos de $\delta^{15 N}$ que o esperado para espécies nectarívoras. Os valores de $\delta 15 \mathrm{~N}$ destas espécies foram mais altos que os da espécie Glyphonycteris behnii, que é considerada uma espécie onívora. Contudo estas três espécies são similares quanto aos valores de $\delta 13 \mathrm{C}$, estando todas dentro da faixa de fonte de alimento C3. Apesar de G. behnii ser a mais restrita á dieta C3, dentre as três (Figura 10).

As espécies Phyllostomus discolor, Phyllostomus hastatus, Molossops temninckii apresentaram discriminações isotópicas de $\delta^{15 \mathrm{~N}}$ típicas de espécies insetívoras. As três espécies contêm em sua dieta itens alimentares provenientes de fontes tanto C3, como C4 (Figura 10). As espécies Cynomops planirostris, Desmodus rotundos e Eptesicus diminutus, apesar de comporem guildas diferentes apresentaram valores de $\delta 15 \mathrm{~N}$ similares. Porém, enquanto $C$. planirostris possui valores medianos de $\delta 13 \mathrm{C}$, ou seja, fontes provenientes tanto de C3 quanto de C4, o D. rotundus possui o menor valor desta assinatura isotópica entre todas as espécies, representando fontes alimentares exclusivamente C4 (Figura 10).

$\delta{ }_{15} \mathrm{~N}$ 
Figura 8. Gráfico de dispersão das guildas de morcegos de remanescentes de Cerrado do Distrito Federal em relação à fonte alimentar $\left(\delta^{13 C}\right)$ e ao nível trófico $(\delta 15 N)$.

Figura 9. Gráfico de dispersão dos morcegos divididos em guildas de animalívoros e fitófogos em relação àfonte alimentar $\left(\delta^{13 C}\right)$ (gráfico "a") e ao nível trófico $\delta 15 \mathrm{~N}$ (gráfico "b").

Figura 10. Espécies de morcegos de fragmentos de Cerrado do Distrito Federal em relação ao hábito alimentar, mensurado por meio da origem alimentar $\left(\delta^{13 C}\right)$ (gráfico "A") e do nível trófico (ס15N) (gráfibo "B") de cada espécie.

\section{Discussão}

Assembleia de morcegos

A riqueza total de espécies aqui encontrada (18) é similar à média de riqueza encontrada em outros estudos realizados no Cerrado. Alguns estudos realizados neste bioma mostram uma média de 15-25 espécies registradas para diferentes regiões (Willig 1983, Pedro e Taddei 1997, Gargaglione et al. 1998, Rodrigues et al. 2002, Falcão et al 2003). Outras pesquisas realizadas em fragmentos de Cerrado possuem um registro de riqueza de espécies inferior a encontrada no presente trabalho (e.g. Loureiro e Gregorin 2015). Todas as espécies registradas no presente estudo têm sido comumente capturadas para a região (Marinho-Filho 2012). 
A predominância de morcegos da família Phyllostomidae tanto nos remanescentes urbanos, como nos rurais, é um resultado esperado devido ao método de captura utilizado (redes-de-neblina) e também à grande riqueza desta família em toda região neotropical (Fenton et al. 1992). Em geral, os estudos taxonômicos em região Neotropical mostram a dominância de espécies de filostomídeos (Marinho-Filho 1985, Aguiar 1994, Zortéa e Alho 2008). Morcegos da família Vespertilionidae se mostram hábeis em detectar as redes, enquanto os Molossidae possuem hábito de forragearem em alturas maiores (Pedro e Taddei 1997). Apesar do método de captura ser seletivo para algumas famílias de morcegos, o mesmo método foi utilizado em todos os locais e por meio desta padronização é possível comparar os ambientes estudados. A maior abundância de indivíduos molossídeos em matriz urbana pode está relacionada com a maior densidade de insetos nestas áreas, devido à alta luminosidade das cidades (Bredt et al. 1996, Reis et al. 2006, Begon et al. 2007).

A maior abundância da espécie Artibeus lituratus está provavelmente associada ao seu hábito de vida oportunista, já que esta espécie é capaz de se adaptar a vários ambientes e condições, e possui dieta variada (Sazima et al. 1994, Zortéa e Chiarello 1994, De Knegt et al. 2005). Reis et al (2012) mostram que A. lituratus habita vários tipos de ambientes no Paraná. Taddei (1983) e Sazima et al. (1994), registaram várias espécies de plantas que são consumidos por $A$. lituratus em áreas urbanas, mostrando que esta espécie se adapta bem a ambientes antropizados. O ambiente urbano pode oferecer recursos adequados para os morcegos. Artibeus lituratus é considerado predominantemente frugívoro, mas também se alimenta de insetos, pólen e néctar e pode usar outros conteúdos como fonte adicional de alimento (Kunz e Diaz, 1995).

Outros estudos também mostram esta espécie consumindo vários itens alimentares (De Knegt et al. 2005, Ferreira et al. 2010).

A segunda espécie mais abundante, Glossophaga soricina, foi também encontrada como espécie dominante por Zortéa e Alho (2008) no centro-oeste do Cerrado, representando $30 \%$ dos indivíduos coletados. Raros são os estudos que registram ocorrência de poucos indivíduos de $G$. soricina ou mesmo ausência desta espécie no Brasil (Zortéa e Alho 2008). Esta espécie se abriga em vários locais, como ocos de árvores, grutas, edifícios ou pontes (Fenton et al. 2001). Devido ao hábito generalista desta espécie, ela ocorreu de forma equilibrada nos dois tipos de ambiente.

No presente estudo, A. planirostris foi mais abundante em fragmentos de matriz rural, o que demonstra que esta espécie frugívora se adapta bem a este ambiente. A baixa abundância de $A$. planirostris (um indivíduo) em matriz urbana é semelhante aos resultados encontrados em outros estudos que mostraram que esta espécie não é comum em ambiente urbano (Silva et al. 1996, Perini et al. 2003, De Knegt et al. 2005, Ortêncio-Filho et al. 2005, Lima 2008). Porém, um estudo realizado na cidade de Campo Grande demonstra que A. planirostris foi a segunda espécie mais abundante em ambiente urbano (Ferreira et al 2010). Os autores atribuem esta elevada abundância contraditória aos 
outros estudos à aparente maior densidade desta espécie na porção sul dos domínios do Cerrado e do Pantanal (Bordignon 2006, Camargo et al. 2009)

Os resultados encontrados no presente trabalho corroboram a hipótese de que as assembleias de morcegos são diferentes entre as matrizes urbana e rural, em termos de composição, riqueza e diversidade de espécies. A diversidade encontrada na matriz rural neste trabalho é maior que a encontrada em estudo realizado no estado de Minas Gerais (Pedro e Taddei 1997). Em estudo realizado em remanescentes de Cerrado inseridos em matriz de pasto e plantação a diversidade foi menor $\left(H^{\prime}=1.6\right)$ que a encontrada na matriz rural do presente estudo $\left(H^{\prime}=2.1787\right)$. A diversidade de morcegos de matriz urbana $\left(H^{\prime}=1.8704\right)$ foi maior que a encontrada em estudo realizado em remanescentes urbanos $(1,65)$. Em trabalho realizado por Duchamp (2004), a diferença na diversidade de morcegos de diferentes ambientes pode também ser observada, porém sob aspectos mais específicos, quando se comparou apenas duas populações em ambiente rural e urbano. Flynn et al. (2009) observaram esta diferença ao compararem paisagens naturais e áreas de agricultura e verificaram que o número de espécies e a diversidade em comunidades de mamíferos e aves caíram dramaticamente como a intensificação do uso da terra para fins agrícolas.

As ocorrências únicas e exclusivas de matriz rural das espécies Chiroderma doriae e Chiroderma villosum são justificadas pela raridade destas espécies em outros locais de Cerrado, como em Campo Grande que em estudo realizado recentemente foram registradas pela primeira vez e foram raras também (Ferreira et al. 2010). Este resultado para $C$. doriae era esperado, já que, segundo alguns autores, esta espécie é escassamente registrada no centro-oeste (Taddei 1979, Gregorin 1998). Loureiro e Gregorin (2015) mostraram também a ocorrência única de $C$. doriae em paisagens fragmentadas no Cerrado de Minas Gerais. Estas duas espécies são bastante especialistas nos hábitos alimentares, o que limita suas ocorrências (Nogueira et al. 2003). Além de apresentarem dieta muito especializada em consumo de espécies silvestres de Ficus spp. (Nogueira e Peracchi 2003), o que desfavorece a presença delas em ambientes urbanos.

A espécie Glyphonycteris behnii ocorreu exclusivamente em matriz rural e é considerada uma espécies rara, possuindo apenas oito registros de indivíduos em cinco localidades diferentes (Williams e Genoways, 2007, Zortéa e Alho 2008, Portella 2010, Gregorin et al. 2011). Em 2011 esta espécie foi registrada pela quarta vez no bioma Cerrado (Gregorin et al. 2011). Glyphonycteris behnii é considerada por alguns autores como restrita ao Cerrado (Gregorin et al. 2011) e está ameaçada de extinção no Brasil, na categoria "vulnerável" da lista brasileira de espécies ameaçadas (MMA 2014).

A ocorrência de Lonchophylla dekeyseri chama atenção pelo fato desta espécie ser considerada endêmica do Cerrado e estar listada como ameaçada no Brasil (MMA 2014). O fato dela ocorrer apenas em ambiente rural era esperado já que esta espécie é cavernícola, e é na matriz rural que se concentram as cavernas de Brasília, principalmente na porção Norte do Distrito Federal (Martins et al. 2005 Apenas seis populações de $L$. dekeyseri são conhecidas e todas elas estão associadas a regiões 
cársticas (Aguiar et al. 2010). Esta é uma espécie muito associada ao abrigo, já que durante o período de forrageio retorna uma ou duas vezes ao abrigo (Coelho e Marinho- Filho 2002). Isso indica que esta espécie possui requerimentos específicos que apenas o ambiente nativo (remanescente no rural) está conseguindo oferecer.

A maior abundância de $D$. rotundus em fragmentos rurais (12), comparada com a ocorrência de um indivíduo em ambiente urbano é explicada pelo fato da matriz rural conter áreas de pastagem e criação de outros mamíferos, que servem de presa fácil para estes morcegos hematófagos. A abundância elevada desta espécie foi também registrada

por Zortéa e Alho (2008), no estado de Goiás, onde os autores atribuem este resultado á presença de fazendas e gados próximos ao ponto de coleta.

As espécies $A$. geoffroyi e $C$. planirostrris ocorreram exclusivamente em matriz urbana. Porém a ocorrência exclusiva de $A$. geoffroyi provavelmente é aleatória, pois esta espécie é comumente encontrada no Cerrado, sendo uma das espécies mais abundantes no bioma (Willig 1983, Zortéa e Alho 2008). Em matriz rural do Distrito Federal esta espécie é também encontrada. Dados não publicados extraídos do Laboratório de Morcegos da Universidade de Brasília confirmam a ocorrência de A. geoffroyi na Estação Ecológica de Águas Emendadas (ESECAE) (15³5' 22,4" S, 47 41' 49,0" W) que é localizada em Planaltina, bem próxima a um dos pontos de coleta $\left(15^{\circ} 36^{\prime} 32.51^{\prime \prime} S\right.$, $47^{\circ} 36^{\prime} 48.13^{\prime \prime} \mathrm{W}$ ) considerado aqui de matriz rural. A presença de $C$. planirostrris em ambiente urbano pode ser explicada pela presença de edificações, os principais tipos de abrigo dos morcegos insetívoros (Bredt et al. 1996). A matriz urbana por ser caracterizada pela concentração populacional humana pode favorecer a persistência de algumas espécies de morcegos mais que as outras, pela presença de pavimentação e edificações, além de possuir áreas verdes com plantas nativas dentro das cidades e pomares residenciais (Rodrigues et al. 1994). Estudo realizado por Reis et al. (2006) mostra que várias espécies de morcegos são bem adaptadas á área urbana.

O fato das outras espécies quais? terem ocorrido nos dois tipos de matriz pode ser explicado pela hipótese de Malcolm (1997), que afirma que diferenças na capacidade que pequenos mamíferos e pássaros insetívoros tropicais possuem em atravessar matriz de habitat são atribuídas a diferenças na percepção que cada organismo tem de matriz desmatada. Este autor sugere que há pequenas diferenças na percepção do que é fragmento de habitat e matriz desmatada para vertebrados noturnos (Malcolm 1997). Os morcegos são apontados por terem grande capacidade de atravessar habitat com matriz desmatada e muitas espécies de fato tem demonstrado esta habilidade (e.g. Fleming e Heithaus 1986, Galetti e Morellato 1994). Uma vez que os recursos utilizados pelos morcegos são muitas vezes separados por grandes distâncias, através do processo de fragmentação, algumas espécies conseguem voar vários quilômetros entre abrigos e sítios de forrageio cada noite (Elmore et al. 2005, Brothers et al. 2006). Desta forma, algumas espécies de morcegos das áreas estudadas conseguem visualizar os fragmentos e suas respectivas matrizes como uma paisagem unificada. 
Vale ressaltar que espécies com hábitos generalistas podem aproveitar as oportunidades criadas pela paisagem modificada pelo homem, seja urbana ou rural,

possivelmente aquelas espécies de alta mobilidade (Medellín et al. 2000). Outras espécies podem ser menos móveis ou possuir exigências por habitat especializado, tornando-as incapazes de se mover por longas distâncias e usar outros habitats na paisagem, ou seja, diferentes espécies dentro de uma mesma sub-família podem responder diferentemente á fragmentação (Medellín et al. 2000, Reis et al. 2006, Willig et al. 2007). Assim, há uma tendência de que o tipo de matriz selecione algumas espécies para permanecerem ou não no local. Alguns estudos mostram que o padrão de resposta das espécies de morcegos a perturbações antropogênicas está relacionado com aspectos espécieespecífico da sua ecologia de forrageio (Schulze et al. 2000, Gorresen e Willig 2004). Por exemplo, morcegos frugívoros e nectarívoros geralmente exploram melhor os recursos alimentares após a conversão da vegetação nativa para agricultura (Willig 2007). Em relação à fragmentação este padrão também é observado (Debinski e Holt 2000, Bernard e Fenton 2006).

A não estabilização da curva de rarefação pode estar relacionada com ao esforço de captura. $O$ esforço de captura por meio de credes de neblina do presente trabalho foi de 12.960 .000 h.m²-1, obtendo 18 espécies. Enquanto estudo realizado no Jalapão, com este mesmo método teve esforço maior (91.275,6 h.m2-1), e foram capturadas 10 espécies a mais que as encontradas aqui (Gregorin et al. 2011). Vale ressaltar que o método de captura por rede é seletivo para algumas famílias. Talvez, o uso de métodos como monitoramento acústico, poderia aumentar a o número e a diversidade de espécies, como observado por MacSwiney (2008), que mostra que a metodologia de bioacústica adicionou $30 \%$ a mais de espécies à sua lista.

\section{Hábito alimentar dos morcegos $X$ matrizes urbana e rural}

Quando se comparou o nível trófico e a fonte alimentar das espécies entre os dois tipos de ambiente, não foi observada diferença de hábito alimentar das guildas alimentares dos morcegos de acordo com o tipo de matriz (Figuras 5, 6 e 7). Assim a segunda hipótese do presente trabalho, de que a diferença das assembleias de morcegos entre as duas matrizes poderia ser enxergada a partir da dieta destes organismos foi refutada. As análises da dieta destes morcegos não segue o mesmo padrão de resposta à fragmentação, comparadas com as análises dos descritores das assembleias de morcegos. Este fato mostra que independente do tipo de matriz que circunda o fragmento, a maioria das espécies está se alimentando de forma similar, ou seja, a dieta

dos morcegos capturados não está refletindo as características dos diferentes uso da terra nas duas matrizes.

Em relação à dieta refletir a característica das matrizes onde os morcegos foram capturados (e provte aonde vivem) foi refutada uma vez que não houve diferença na composição isotópica de 
nitrogênio e carbono entre os morcegos das duas matrizes (Figuras 6 e 7). Ou seja, os morcegos comem alimento isotopicamente mais nativo e não narivo da mema forma nas duas matrizes.

No entanto, observei que algumas espécies não podem ser classificadas facilmente em distintas guildas alimentares de acordo com a composição isotópica, já que os valores de $\delta 15 \mathrm{~N}$ se desviam um pouco da média os valores esperado para cada guilda. Como a maioria destas espécies são da família Phyllostomidae, observou-se que estas espécies possuem uma dieta bem variada. O que corrobora com o encontrado por Rex et al. (2010), que indica que filostomídeos se especializaram sucessivamente em dietas distintas sem alterar a sua capacidade para exploração tipos de alimentos variados. Essa onivoría, se por um lado, torna os morcegos oportunistas, por outro pode promover a alta diversidade de filostomídeos.

Observa-se uma separação da dieta entre os morcegos animalívoros e os fitófagos, o que é explicado pelo fato de que os recursos alimentares utilizados pelos fitófagos são apenas encontrados na vegetação nativa de Cerrado. Os frutos e o néctar das flores que constituem a dieta destes animais não são encontrados em pastos ou em plantações cultivadas, que são a fonte de alimento do tipo C4. Alguns morcegos que estão consumindo tanto alimentos C3 como C4, classificados como onívoros, aumentam sua amplitude de nicho, junto com a probabilidade de consumirem alimentos das duas fontes. Pode ser também apenas uma indicação de que os morcegos estão complementando sua dieta com outro tipo de alimento, e por isso os valores altos de $\delta^{15 \mathrm{~N}}$ para os fitófagos.

No geral, os morcegos fitófagos foram os que mais se alimentaram de fonte $\mathrm{C} 3$, refletindo 0 resultado esperado, já que os itens alimentares desta fonte estão presentes em derivados de flores e frutos nativos do Cerrado, que apenas são encontrados em vegetação nativa. Assim a vegetação de fonte C4 não serve de alimento para os animais desta guilda. Vale ressaltar que nem todos os indivíduos frugívoros estão dentro da faixa de valores de fonte $\mathrm{C} 3$, o que indica que estes animais podem estar se alimentando também de insetos ou outro tipo de alimento que possa provir de fontes C4. Isto pode ser resultado de um incremento na dieta dos morcegos frugívoros, por falta do recurso

base (fruto) da alimentação destes animais, já que os ambientes podem não estar oferecendo os recursos suficientes para viabilidade destas populações devido à fragmentação gerada pelas mudanças do uso de solo.

Desta forma, os morcegos frugívoros e nectarívoros se diferenciam dos hematófagos em relação à obtenção de alimento. Os hematófagos conseguem ter acesso mais fácil ás presas que contém no sangue a fonte C4 de alimento como demonstrado por Salgado et al. (2014). Esses autores mostraram que $D$. rotundus se alimenta do gado no Cerrado, alterando inclusive a cadeia de predadores de cavernas na região. Assim como mostrado por Voigt e Kelm (2006), a ocorrência de $D$. rotundus está ligada a presença do hospedeiro (gado) e há uma a preferência dos morcegos ao gado 
sobre mamíferos nativos, provavelmente porque o gado é um recurso mais previsível do que hospedeiros naturais isolados.

Os morcegos onívoros se alimentam de vários itens alimentares, aumentando a chance destes organismos de consumirem os dois tipos de fontes alimentares analisados. Do mesmo modo, os insetívoros consomem presas que possuem grande mobilidade, que conseguem consumir tanto plantas nativas, como plantas provenientes de plantações cultivadas, pastos e qualquer outra vegetação classificada como C4. Assim, estas duas guildas apresentaram uma dieta contendo itens alimentares provenientes tanto de fonte $C 3$, como $C 4$, mantendo os valores de $\delta^{13 C}$ em níveis intermediários.

As espécies frugívoras, Artibeus lituratus, Artibeus planirostris, Carollia perspicillata e Sturnira lilium, possuem composições isotópicas de nitrogênio compatível com uma dieta mais enriquecida, como uma dieta composta por insetos. Para C. perspicillata este mesmo padrão foi observado por York e Billings (2009), os quais verificaram que esta espécie tem uma dieta muito mais ampla do que se esperava. Em um estudo realizado por Munõz-Lazo (2013), em área fragmentada, foi observado por meio de análises com isótopos estáveis, que a contribuição relativa de insetos na dieta de $A$. lituratus e $C$. perspicillata foi de $95 \%$ e $85 \%$, respectivamente. Como os tecidos do corpo são formados principalmente por proteínas, é válido pensar que alguns morcegos fitófagos supram suas necessidades consumindo proteínas como recursos adicionais (Thomas 1984, Herrera et al. 2006). Então, provavelmente, estas espécies estão tendo a necessidade de complementar sua dieta com itens alimentares mais ricos em proteína. Na zona neotropical tem-se observado que os morcegos frugívoros possuem sua dieta baseada em alimentos que são pobres em nitrogênio e como complemento alimentar utilizam insetos para suprir a demanda de proteínas exigida

pelos organismos (Gardner 1977, Thomas 1984, Courts 1998). Há controvérsia no caso de Sturnira lilium, em que outro estudo mostrou que esta espécie não necessita de complementar sua dieta, obtendo sua maior necessidade de proteínas a partir de frutas (Herrera et al. 2001).

A espécie Chiroderma villosum atua como predadora de sementes e não dispersora, utilizando uma estratégia bem especializada de predação, ingerindo um rico conteúdo de sementes e descartando uma grande quantidade de fragmentos do alimento capturado, ou seja, ela consome a semente em adição à polpa de fruta para melhoria na aquisição de nutrientes (Nogueira et al. 2003). Isso justifica o fato dela está consumindo alimentos de origem C3. Em relação à composição isotópica de nitrogênio de $C$. villosum foi observado que o seu nível trófico está acima do esperado, já que espécies frugívoras possuem valores de $\mathrm{N}$ mais baixos.

A espécie Dermanura sp. se destacou por ser a única entre as frugívoras que apresentou uma baixa assinatura isotópica $(\delta)$ de $\mathrm{N}$, o que representa bem esta guilda, considerada uma espécie de amplitude de nicho pequena. Além disso, seus valores de carbono se mantiveram na faixa de fonte C3, o que demonstra que esta espécie está se alimento apenas de fruta. Outros estudos sugerem que 
algumas espécies fitófagas sobrevivem bem com uma dieta apenas baseada em frutos, sem ter que adicionar outros itens de alto teor proteico (Herbst 1986, Delorme e Thomas 1996). Este fato foi confirmado por Foster (1978), o qual afirma que alguns frutos podem ser fontes adequadas de

nitrogênio. Assim, a espécie Dermanura sp. possui requerimentos bem específicos aos fragmentos, já que a vegetação nativa de Cerrado possui em média estes valores apresentados por esta espécie. Isto pode também explicar a baixa abundância desta espécie, por ser mais especialista, se torna uma espécie mais sensível ás alterações ambientais. Através destas duas ideias contrastantes podemos perceber que é possível a existência de guildas de morcegos frugívoros com espécies que sobrevivem com níveis diferentes de nitrogênio assimilados pelos organismos, o que pode explicar o resultado variado de composições isotópicas de nitrogênio para os morcegos frugívoros.

\section{REFERÊNCIAS BIBLIOGRÁFICAS}

Aguiar L, Bernard E, Machado RB (2014) Habitat use and movements of Glossophaga soricina and Lonchophylla dekeyseri (Chiroptera: Phyllostomidae) in a Neotropical savannah. Zoologia (Curitiba) 31(3): 223-229.

Aguiar LMS (1994) Comunidades de Chiroptera em três áreas de Mata Atlântica em diferentes estádios de sucessão - Estação Biológica de Caratinga, Minas Gerais. Dissertação de Mestrado, Instituto de Ciências Biológicas, Universidade Federal de Minas Gerais, Belo Horizonte.

Aguiar LMS, Bernard E, Machado RB (2014) Habitat use and movements of Glossophaga soricina and Lonchophylla dekeyseri (Chiroptera: Phyllostomidae) in a Neotropical savannah. Zoologia (Curitiba) 31(3): 223-229.

Aguiar LMS, Brito D, Machado RB (2010) Do current vampire bat (Desmodus rotundus) population control practices pose a threat to dekeysers nectar bat's (Lonchophylla dekeyseri) long-term persistence in the Cerrado? Acta Chiropterol. 12:275-282. http://dx.doi. org/10.3161/150811010X537855.

Aguiar LMS, Marinho-Filho JS (2004) Activity patterns of nine phyllostomid bat species in a fragment of the Atlantic Forest in southeastern Brazil. Rev Bras Zool 21(2):385-390.

Aguirre LF, Lens L, Van Damme R, Matthysen E (2003) Consistency and variation in the bat assemblages inhabiting two forest islands within a Neotropical savanna in Bolivia. Journal of Tropical Ecology,19(04): 367-374.

Alho CJR, Martins E, de S.(Org.) (1999) De grão em grão o cerrado perde espaço. Brasília: WWF, $1995.66 \mathrm{~m}$ p.Andren, Henrik. "Effects of habitat fragmentation on birds and mammals in landscapes with different proportions of suitable habitat: a review. Oikos (1994): 355-366. Arruda 
MB, Gestão integrada de ecossistemas, a escala da conservação da biodiversidade expandida. Brasília: IBAMA 11p.

Almeida SP, Ribeiro JF. Cerrado: ecologia e flora. Embrapa (13):384-398.

Alvarez T, Gonzalez-quintero EL (1970) Anilisis polinico del contenido Gistrico de murcielagos Glossophaginae de Mexico. Instituto Polit\&cnico Nacional. Anales de la Escuela Nacional de Ciencias Biologicas 18: 137-165.

Andersen K (1906) On the bats of the genera Micronycteris and Glyphonycteris. Ann.

Mag. Nat. Hist. 18(7):50-65.

Anderson LO, Rojas EHM, Shimabukuro YE (2003) Avanço da soja sobre os ecossistemas cerrado e floresta no Estado do Mato Grosso.Simpósio Brasileiro de Sensoriamento Remoto (11): 19-25.

Andrén H, (1994) Effects of Habitat Fragmentation on Birds and Mammals in Landscapes with Different Proportions of Suitable Habitat: A Review. Oikos (71): 355-366.

Antongiovanni M, Metzger JP (2005) Influence of matrix habitats on the occurrence of insectivorous bird species in Amazonian forest fragments. Biological Conservation 122(3): 441-451.

Barcellos AO (1996) Sistemas extensivos e semi-intensivos de produção: pecuária bovina de corte nos cerrados. In: Pereira RC, Nasser LCB (eds.). Biodiversidade e produção sustentável de alimentos e fibras nos Cerrados. VIII Simpósio sobre o Cerrado. Empresa Brasileira de Pesquisa Agropecuária (Embrapa Cerrados), Planaltina, Brasil. pp 130-136.

Begon M, Townsend CR, Harper JL (2007) Ecologia: de indivíduos a ecossistemas. 4 ed. Artmed, Porto Alegre, p 740.

Begon M, Townsend CR, Harper JL (2007) Ecologia: de indivíduos a ecossistemas.4. ed. Porto Alegre: Artmed. 752p.

Bendassolli JA, Mortatti J, Trivelin PCO, de Flgnoto R, Bonassi JA, Tavares GA (2002) Reciclagem de cobre proveniente de analisador automático de carbono e nitrogênio. Química Nova 25(2): 312315.

Ben-David MA, Flynn RW, Schell DM (1997) Annual and seasonal changes in diets of martens: evidence from stable isotope analysis. Oecologia 111: 280-291.

Bernard E (2001) Vertical stratification of bat communities in primary forests of Central Amazon, Brazil. J Trop Ecol 17:115-126. 
Bernard E, Aguiar L, Machado RB (2011) Discovering the Brazilian bat fauna: A task for two centuries?.Mammal Review 41(1): 23-39.

Bernard E, Fenton MB (2002) Species diversity of bats (Mammalia: Chiroptera) in forest fragments, primary forests and savannas in Central Amazonia, Brazil. Can J Zool 80:1124-1140.

Bernard E, Fenton MB (2003) Bat mobility and roosts in a fragmented landscape in central Amazonia, Brazil. Biotropica 35(2):262-277.

Bernard E, Fenton MB (2007) Bats in a fragmented landscape: species composition, diversity and habitat interactions in savannas of Santarém, Central Amazonia, Brazil. Biological Conservation 134(3): 332-343.

Bezerra LMC, Júnior JC (2004) O Desenvolvimento Agrícola da Região centro-oeste e as transformações no espaço agrário do estado de Goiás. Caminhos de Geografia 2(12) 29-49.

Bianconi GV (2009) Morcegos frugívoros no uso do hábitat fragmentado e seu potencial para recuperação de áreas degradadas: subsídios para uma nova ferramenta voltada à conservação.

Bianconi GV, Mikich SB, Pedro WA (2006) Movements of bats (Mammalia, Chiroptera) in Atlantic Forest remnants in southern Brazil.Revista Brasileira de Zoologia, 23(4): 1199-1206.

Bobbink R, Hicks K, Galloway J, Spranger T, Alkemade R, Ashmore M, De Vries W (2010) Global assessment of nitrogen deposition effects on terrestrial plant diversity: a synthesis. Ecological applications 20(1): 30-59.

Bobrowiec PED, Gribel R (2010) Effects of different secondary vegetation types on bat community composition in Central Amazonia, Brazil.Animal Conservation 13(2): 204-216.

Bobrowiec PED, Oliveira PE (2012) Removal effects on nectar production in bat- pollinated flowers of the Brazilian Cerrado. Biotropica 44 (1): 1-5.

Borcard D, Gillet F, Legendre P (2011). Numerical ecology with R. Springer Science \& Business Media.pp 116.

Bordignon MO (2006) Diversidade de morcegos (mammalian, chiroptera) do complexo Aporé-Sucuriú, Mato Grosso do Sul, Brasil. Rev. Bras. Zool. 23(4):1002-1009.

Borges FJA (2009). Efeitos da fragmentação sobre o sucesso reprodutivo de aves em uma região de Cerrado no Distrito Federal. Dissertação (Mestrado em Ecologia)- Universidade de Brasília, Brasília, p 46. 
Boutton TW (1996) Stable carbon isotope ratios of soil organic matter and their use as indicators of vegetation and climate change. In: Boutton TW, Yamasaki TW, SI (Ed.), Mass spectrometry of soils. New York: Marcel Dekker, p.47-82.

Bray JR, Curtis JT (1957) An ordination of the upland forest communities of southern Wisconsin. Ecol Monogr 27:325-349.

Brazil (1984) Atlas do Distrito Federal. Brasília. Secretaria de Educação e Cultura/CODEPLAN (1): 78.

Bredt A, Uieda W (1996) Bats from urban and rural environments of the Distrito Federal, mid-western Brazil. Chiropt. Neotrop. (2):54-57.

Broders HG, Forbes GJ, Woodley S, Thompson ID (2006) Range extent and stand selection for roosting and foraging in forest-dwelling northern long-eared bats and little brown bats in the greater Fundy ecosystem, New Bruns- wick. J Wildl Manage 70(5): 1174-1184.

Brooks T, Tobias J, Balmford A (1999) Deforestation and bird extinctions in the Atlantic forest. Animal Conservation (2): 211-222.

Bustamante MMC, Martinelli LA, Silva DA, Camargo PB, Klink CA, Domingues TF, Santos RV (2004) $15 \mathrm{~N}$ natural abundance in woody plants and soils of central Brazilian savannas (cerrado). Ecological Applications 14(4): 200-213.

Calaça AM, de Melo FR, De Marco Junior P, de Almeida Jácomo AT, Silveira L (2010) A influência da fragmentação sobre a distribuição de carnívoros em uma paisagem de cerrado. Neotropical Biology and Conservation, 5(1): 31-38.

Camargo G, Fischer E, Gonçalves F, Fernandes G, Ferreira S (2009) Morcegos do Parque Nacional da Serra da Bodoquena, Mato Grosso do Sul, Brasil. Chiropt. Neotrop. 15(1): 417-424.

Carvalho FM, De Marco P, Ferreira LG (2009) The Cerrado into-pieces: habitat fragmentation as a function of landscape use in the savannas of central Brazil. Biological Conservation, 142(7):1392-1403.

Castro Luna AA, Sosa VJ, Castillo Campos G (2007) Bat diversity and abundance associated with the degree of secondary succession in a tropical forest mosaic in south eastern Mexico. Animal Conservation 10(2): 219-228.

Cerqueira R, Brant A, Nascimento MT, Pardini R (2003) Fragmentação: alguns conceitos. In: Rambaldi, Denise Marçal, e Daniela América Suárez de Oliveira. In: Fragmentação de 
ecossistemas: causas, efeitos sobre a biodiversidade e recomendações de políticas públicas. Brasília, DF: Ministério do Meio Ambiente, Secretaria de Biodiversidade Florestas (1):24-40.

Coelho DC, Marinho-Filho J (2002) Diet and activity of Lonchophylla dekeyseri (Chiroptera, Phyllostomidae) in the Federal District, Brazil.Mammalia 66(3): 319- 330.

Coletta LD, Nardoto GB, Latansio-Aidar SR, da Rocha HR, Aidar MPM, Ometto JPHB (2009) Isotopic view of vegetation and carbon and nitrogen cycles in a Cerrado ecosystem, southeastern Brazil. Sci. Agric. (66): 467-75.

Colli GR, Bastos RP, Araújo AB (2002) The character and dynamics of the Cerrado herpetofauna. In: Oliveira, P.S., Marquis, R.J. (Eds.), The Cerrrados of Brazil: Ecology and Natural History of a Neotropical Savanna. Columbia University Press, New York, pp. 223-241.

Corrêa BS, Passamani M, de Moura AS (2011) Avaliação do efeito borda na distribuição da avifauna em fragmentos florestais de Cerrado.Revista Agrogeoambiental 3(3).

Cosson JF, Pons JM, Masson D (1999) Effects of forest fragmentation on frugivorous and nectarivorous bats in French Guiana.Journal of Tropical Ecology, 15(04): 515-534.

Crosson CE, Willis JA, Potter DE (1990) Effect of the calcium antagonist, nifedipine, on ischemic retinal dysfunction. J. Ocul. Pharmacol. (6): 293-299.

Cryan PM, Bogan MA, Rye RO, Landis GP, Kester CL (2004) Stable hydrogen isotope analysis of bat hair as evidence for seasonal molt and long-distance migration. Journal of Mammalogy 85(5): 995-1001.

Cryan PM, Stricker CA, Wunder MB (2012) Evidence of cryptic individual specialization in an opportunistic insectivorous bat. Journal of Mammalogy 93(2): 381-389.

Cullen JR, L. et al. (2006) Métodos de estudos em biologia da conservação e manejo da vida da Nóbrega, Ricardo Campos, e José Imaña Encinas. "Uso atual do solo do projeto ecomuseu do cerrado." Revista Árvore 30 (1): 117-122.

Cunha NL, Fischer E, Santos CF (2011) Bat assemblage in savanna remnants of Sonora, central$\begin{array}{llll}\text { western } & \text { Brazil. } & \text { Biota }\end{array}$ http://www.biotaneotropica.org.br/v11n3/en/abstract?inventory+bn03311032011

da Silva GBM, Pedroni F (2014) Frugivoria por aves em área de Cerrado no município de Uberlândia, Minas Gerais. Revista Árvore 38(3):433-442. 
da Silva Jr AP, Pontes ARM (2008) The effect of a mega-fragmentation process on large mammal assemblages in the highly-threatened Pernambuco Endemism Centre, north-eastern Brazil. Biodiversity and conservation 17(6): 1455-1464.

Dammhahn M, Goodman SM (2014) Trophic niche differentiation and microhabitat utilization revealed by stable isotope analyses in a dry-forest bat assemblage at Ankarana, northern Madagascar. Journal of Tropical Ecology 30(02): 97-109.

Darimont CT, Reimchen TE (2002) Intra hair stable isotope analysis implies seasonal shift to salmon in grey wolf diet. Canadian Journal of Zoology 80:1638-1642.

De knegt LV, Silva JA, Moreira EC, Sales GL (2005) Morcegos capturados no município de Belo Horizonte, 1999-2003. Arq. Bras. Med. Vet. Zootec. (57): 576- 583.

de Lima MG, Gascon C (1999) The conservation value of linear forest remnants in central Amazonia. Biological Conservation, 91(2): 241-247.

Deb D (1997) Trophic uncertainty vs. parsimony in food web research, Oikos 788:191- 194.

Debinski DM, Holt RD (2000) A survey and overview of habitat fragmentation experiments. Conservation biology, 14(2): 342-355.

Delorme M, Thomas DW (1996) Nitrogen and energy requirements of the short-tailed fruit bat (Carollia perspicillata): fruit bats are not nitrogen constrained. Journal of Comparative Physiology B 166(7): 427-434.

Demots RL, Novak JM, Gaines KF, Gregor AJ, Romanek CS, Soluk DA (2010) Tissue- diet discrimination factors and turnover of stable carbon and nitrogen isotopes in Peromyscus leucopus. Canadian Journal of Zoology 88: 961 - 967.

DeNiro MJ, Epstein S (1981) Influence of diet on the distribution of nitrogen isotopes in animals. Geochimica et Cosmochimica Acta 45:341-351.

Denzinger A, e Schnitzler Hans-Ulrich (2013) Bat guilds, a concept to classify the highly diverse foraging and echolocation behaviors of microchiropteran bats. Frontiers in physiology (4): 164.

Des Marais DJ, Mitchell JM, Meinschein WG, Hayes JM (1980) The carbon isotope biogeochemistry of the individual hydrocarbons in bat guano and the ecology of the insectivorous bats in the region of Carlsbad, New Mexico. Geochim. Cosmochim. Acta 44: 2075-2086. 
Dias BFS (1992) Cerrados: Uma Caracterizaça4o. In: Dias BF de S, ed. Alternativas de Desenvolvimento dos Cerrados: Manejo e Conservação dos Recursos Naturais Renovavéis. Brasília, DF, Brazil: FUNATURA. pp 303-333.

Dias BFS (2008) Conservação da Biodiversidade no Bioma Cerrado: Histórico dos impactos antrópicos no Bioma Cerrado. In: Faleiro, Fábio Gelape, e Austeclinio Lopes de Farias Neto. Savanas: desafios e estratégias para o equilíbrio entre sociedade, agronegócio e recursos naturais. Embrapa Cerrados.

Dias, M. Mónica, Luiz F. Aguirre e Rubén M. Barquez (2011) Clave de identificación de los murciélagos del cono sur de Sudamérica. Centro de Estudios en Biología Teórica y Aplicada. Cochabamba, Bolivia.

Diniz JAF (1984) Geografia na agricultura. São Paulo, Difel.

dos Reis NR, Muller MF (1995) Bat diversity of forest and open areas in a subtropical region of south Brazil. Ecologia Austral, 5, 31-36.

Eiten G (1972) The cerrado vegetation of Brazil. The Botanical Review,38(2): 201-341

Eiten G (1983) Classificação da vegetação do Brasil. CNPq, Coordenação Editorial, Brasília, Brasil, pp 65.

Eiten G (1993) A Vegetação do Cerrado. In: Pinto, M.N. (ed.), Cerrado: Caracterização, Ocupação e Perspectivas. Brasília: Universidade de Brasília (1)17-73.

Elmore LW, Miller DA, Vilella FJ (2005) Foraging area size and habitat use by red bats (Lasiurus borealis) in an intensively managed pine landscape in Mississippi. Am Midl Nat 153(2): 405-417.

Emerson JK, Roark AM (2007) Composition of guano produced by frugivorous.s, sanguivorous, and insectivorous bats. Acta Chiropterologica 9(1): 261-267.

Erlich PR, Wilson EO (1991). Biodiversity studies: science and policy. Science, 253(5021):758-72.

Estrada A, Coates-Estrada R (2001) Bat species richness in live fences and in corridors of residual rain forest vegetation at Los Tuxtlas, Mexico. Ecography 24(1): 94- 102.

Estrada A, Coates-Estrada R (2001) Species Composition and reproductive phenology of bats in a tropical landscape at Los Tuxtlas, México. Journal Tropical Ecology 17: 672-646.

Estrada A, Coates-Estrada, R (2002) Bats in continuous forest, forest fragments and in an agricultural mosaic habitat-island at Los Tuxtlas, Mexico. Biological Conservation 103(2):237-245. 
Estrada-Villegas S, Meyer CF, Kalko EK (2010) Effects of tropical forest fragmentation on aerial insectivorous bats in a land-bridge island system. Biological Conservation 143(3): 597-608.

Ethier K, Fahrig L (2011) Positive effects of forest fragmentation, independent of forest amount, on bat abundance in eastern Ontario, Canada.Landscape Ecology 26(6): 865-876.

Ewers RM, Didham RK (2006) Confounding factors in the detection of species responses to habitat fragmentation. Biological Reviews 81(01): 117-142.

Fahring L (2003) Effects of fragmentation on biodiversity. Annual Review of Ecology Evolution and Systematics, 34:487-515.

Fahring L, Merriam G (1994) Conservation of fragmented populations. Conserv. Biol.

$8,50-59$.

Falcão FDC, Rebêlo VF, Talamoni SA (2003) Structure of a bat assemblage (Mammalia, Chiroptera) in Serra do Caraça Reserve, south-east Brazil. Revista Brasileira de Zoologia, 20(2): 347-350.

Faria D (2006) Phyllostomid bats of a fragmented landscape in the north-eastern Atlantic forest, Brazil. Journal of Tropical Ecology 22(05): 531-542.

Faria D, Laps RR, Baumgarten J, Cetra M (2006) Bat and bird assemblages from forests and shade cacao plantations in two contrasting landscapes in the Atlantic Forest of southern Bahia, Brazil. Biodiversity \& Conservation, 15(2): 587-612.

Farquhar GD, Ehleringer JR, Hubick KT (1989) Carbon isotope discrimination and photosynthesis. Annual review of plant biology 40(1): 503-537.

Farrow LJ, Broders HG (2011) Loss of forest cover impacts the distribution of the forest-dwelling tricolored bat (Perimyotis subflavus). Mammalian Biology- Zeitschrift für Säugetierkunde, 76(2): 172-179.

Felfili JM, Sevilha AC, Silva Júnior MC (2001) Comparação entre as unidades fisiográficas Chapada Pratinha, Veadeiros e Espigão Mestre do São Francisco. In:

J.M. Felfili \& M.C. Silva Júnior (orgs.). Biogeografia do bioma Cerrado: estudo fitofisionômico na Chapada do Espigão Mestre do São Francisco. Brasília, Universidade de Brasília. pp 80-94.

Felfili MC, Felfili JM (2001) Diversidade alfa e beta no cerrado sensu stricto da Chapada Pratinha, Brasil. Acta Botanica Brasilica 15(2): 243-254. 
Fenton MB (2013) Evolution of Echolocation. In: Adams AR, Pedersen SC Bat Evolution, Ecology, and Conservation, p 547.

Fenton MB, Acharya L, Audet D, Hickey MBC, Merriman C, Obrist MK, Syme DM (1992) Phyllostomid bats (Chiroptera: Phyllostomidae) as indicators of habitat disruption in the Neotropics. Biotropica 24(3):440-446.

Fenton MB, Bernars E, Bouchard S, Hollis LDS, Johnston CL, Lausen JM., Ratcliffe DK, Riskin JR, Taylor, Zigouris J (2001) The bat fauna of Lama - nai, Belize: roosts and trophic roles. Journal of Tropical Ecology (17): 511-524.

Ferreira CMM, Fischer E, Pulchério-Leite A (2010). Fauna de morcegos em remanescentes urbanos de Cerrado em Campo Grande, Mato Grosso do Sul. Biota Neotropica, 10(3): 155-160.

Fleming TH (1988) The Short-tailed Fruit Bat. The University of Chicago Press, Chicago, pp 365.

Fleming TH (1995) The use of stable isotopes to study the diets of plantvisiting bats. In Ecology, Evolution and Behaviour of Bats (ed. P. A. Racey and S. M. Swift) Oxford: Clarendon Press pp. $99-110$.

Fleming TH, Heithaus ER (1986) Seasonal foraging behavior of the frugivorous bat Carollia perspicillata. Journal of Mammalogy 660-671.

Fleming TH, Hooper ET, Wilson DE (1972) Three Central American bat communities: structure, reproductive cycles, and movement patterns. Ecology 53, 555-569.

Fleming TH, Nuñez RA, Sternberg LDSL (1993) Seasonal changes in the diets of migrant and nonmigrant nectarivorous bats as revealed by carbon stable isotope analysis. Oecologia, 94(1): 7275.

Fleming, TH, Vinicio JS (1994) Effects of nectarivorous and frugivorous mammals on reproductive success of plants. Journal of Mammalogy 845-851.

Flynn DF, Gogol-Prokurat M, Nogeire T, Molinari N, Richers BT, Lin BB, ... DeClerck F (2009) Loss of functional diversity under land use intensification across multiple taxa. Ecology letters 12(1): 2233.

Forman M, Godron M (1986) Landscape ecology. New York: Wiley 619p.

Forman RT (1995). Some general principles of landscape and regional ecology. landscape ecology 10(3):133-142. 
Forman RTT, Godron M (1981) Patches and structural components for a landscape ecology. BioScience (31): 733-740.

Forman RTT, Godron M (1986) Landscape Ecology. John Wiley \& Sons, New York.

Foster MS (1978) Total frugivory in tropical passerines: a reappraisal. Trop Ecol 19:131-154.

Frey-Ehrenbold A, Bontadina F, Arlettaz R, Obrist MK (2013) Landscape connectivity, habitat structure and activity of bat guilds in farmland-dominated matrices. Journal of Applied Ecology, 50(1): 252-261.

Galetti M, Morellato LPC (1994) Diet of the large fruit-eating bat artibeus-lituratus in a forest fragment in brazil. Mammalia 661-665.

Gardner AL (2008) (ed.) Mammals of South America: Volume I. Marsupials, xenarthrans, shrews, and bats Chicago: University of Chicago Press. 669p.

Gargaglioni LH, Batalhão ME, Lapenta MJ, Carvalho MF, Rossi RV, Veruli VP (1998) Mamíferos da Estação Ecológica de Jataí, Luiz Antônio, São Paulo. Papéis Avulsos de Zoologia, 40(17), 267287.GDF-Governo do Distrito Federal. Unidade de Conservação e Área protegidas. Disponível em:<http://www.sucar.df.gov.br/paginas/a secretaria/a secretaria 10.htm/ HYPERLINK "http://www.sucar.df.gov.br/paginas/a_secretaria/a_secretaria_10.htm/\%3eAcesso" $\geq$ HYPERLINK

"http://www.sucar.df.gov.br/paginas/a_secretaria/a_secretaria_10.htm/\%3eAcesso"Acess $\underline{o}$ em 02 dez. 2014.

Gregorin R, Gonçalves E, Aires CC, Carmignotto AP (2011) Bats (Mammalia: Chiroptera) from Estação Ecológica Serra Geral do Tocantins.Biota Neotropica, 11(1), 299-311.

Gaye-Siessegger J, Focken U, Muetzel S, Abel H, Becker K (2004) Feeding level and individual metabolic rate affect $13 \mathrm{C}$ and $15 \mathrm{~N}$ values in carp: implications for food web studies. Oecologia 138: 175-183.

Gehrt SD, Chelsvig JE (2003) Bat activity in an urban landscape: patterns at the landscape and microhabitat scale. Ecological Applications 13(4): 939-950.

Gorresen PM, Willig MR (2004) Landscape responses of bats to habitat fragmentation in Atlantic Forest of Paraguay. J. Mammal. 85: 688-697.

Gregorin R (1998) Extending geographical distribution of Chiroderma doriae Thomas, 1891 (Phyllostomidae, Stenodermatinae). Chiroptera Neotropical, Brasilia (4): 98-

99. 
Gregorin R, Gonçalves E, Aires CC, Carmignotto AP (2011) Bats (Mammalia: Chiroptera) from Estação Ecológica Serra Geral do Tocantins. Biota Neotropica, 11(1), 299-311.

Haines-Young R (2009) Land use and biodiversity relationships. Land Use Policy 26: 178-186.

Hanson, JS, Malanson PG, Armstrong PM (1990) Landscape fragmentation and dispersal in a model of riparian forest dynamics. Ecological modelling 49 (3): 277-296.

Haridasan M (1992) Observations on soils, foliar nutrient concentration and floristic composition of cerrado sensu stricto and cerradão communities in central Brazil. Pp.171-184. In: Furley PA, Proctor J, Ratter JA (eds.) Nature and Dynamics of Forest-Savanna Boundaries. London, Chapman \& Hall Publishing.

Hass A (2002) Efeitos da criação do reservatório da UHE Serra da Mesa (Goiás) sobre a comunidade de aves. Tese de Doutorado, PPG Ecologia, Instituto de Biologia, Universidade Estadual de Campinas, Campinas, SP.

Heithaus ER, Fleming TH (1978) Foraging movements of a frugivorous bat, Carollia perspicillata (Phyllostomidae). Ecol. Monogr. (48): 127-143.

Herbst LH (1986) The role of nitrogen from fruit pulp in the nutrition of the frugivorous bat Carollia perspicillata. Biotropica 39-44.

Herrera LG, Altube B, Díaz W, Gutierrez E, Hobson KA, Sánchez-cordero V (2002) Sources of assimilated protein in five species of New World frugivorous bats, Oecologia 133: 280-287.

Herrera LG, Fleming TH, Findley JS (1993) Geographic variation in carbon composition of the pallid bat, Antrozous pallidus, and its dietary implications. J. Mamm. (74):601-606.

Herrera LG, Fleming TH, Sternberg LS (1998) Trophic relationships in a neotropical bat community: A preliminary study using carbon and nitrogen isotopic signatures. Journal of Tropical Ecology (39): 23-29.

Herrera LG, Hobson KA, Estrada D, Manzo A, Méndez G, Sánchez-cordero V (2001) The role of fruits and insects in the nutrition of frugivorous bats: evaluating the use of stable isotope models. Biotropica (33): 520-528.

Herrera-M LG, Hobson KA, Ramírez PN, Méndez CG, Sánchez-Cordero V (2001) Sources of protein in two species of phytophagous bats in a seasonal dry forest: evidence from stable-isotope analysis. Journal of Mammalogy 82(2): 352-361. 
Hobson KA, Manzo A, Estrada D, Sánchez-Cordero V, Méndez G (2001) The Role of Fruits and Insects in the Nutrition of Frugivorous Bats: Evaluating the Use of Stable Isotope Models1. Biotropica 33(3): 520-528.

Hobson KA, Mclellan BN, Woods J (2000) Using stable-carbon (d13C) and nitrogen (d15N) isotopes to infer trophic relationships among black and grizzly bears in Upper Columbia River Basin, British Columbia. Can. J. Zool. 78: 1332-1339.

IBGE. Instituto Brasileiro de Geografia e Estatística. 2004. Mapa de Biomas do Brasil. Escala 1:5.000.000. Disponível em:

$<$ http://mapas.ibge.gov.br/biomas2/viewer.htm HYPERLINK

"http://mapas.ibge.gov.br/biomas2/viewer.htm">. Acesso em: 08 ago. 2014.

Kalko EKV (1998) Organisation and diversity of tropical bat communities through space and time. Zoology 101(4):281-297.

Kelly JF (2000) Stable isotopes of carbon and nitrogen in the study of avian and mammalian trophic ecology. Canadian Journal of Zoology 78(1): 1-27.

Klingbeil BT, Willig MR (2009) Guild-specific responses of bats to landscape composition and configuration in fragmented Amazonian rainforest. Journal of Applied Ecology, 46(1): 203-213.

Klink CA, Moreira AG (2002) Past and current human occupation, and land use. In: Oliveira, P.S., Marquis, R.J. (Eds.), The Cerrados of Brazil: Ecology and Natural History of a Neotropical Savanna. Columbia University Press, New York pp 69-88.

Kunz TH, Diaz CA (1995) Folivory by leaffractionation in fruit-eating bats, with new evidence from Artibeus jamaicensis. Biotropica (27):106-120.

Kunz TH, Torrez EB, Bauer D, Lobova T, Fleming TH (2011) Ecosystem services provided by bats. Ann. N.Y. Acad. Sci. 1223: 1-38.

Lam MMY, Dominik MC, Karl-Otto R, Kamran S, Elizabeth Y, loanna S (2013) Tracking Diet Preferences of Bats Using Stable Isotope and Fatty Acid Signatures of Faeces Limnological Institute, University of Konstanz, Konstanz, Germany, Department of Migration and Immunoecology, Max Planck Institute for Ornithology, Radolfzell, Germany, Department of Biology, University of Konstanz, Konstanz, Germany. 8(12): e83452-e83452.

Lam MMY, Martin-Creuzburg D, Rothhaupt KO, Safi K, Yohannes E, Salvarina I (2013) Tracking diet preferences of bats using stable isotope and fatty acid signatures of faeces. PloS one, 8(12): e83452. 
Law BS, Anderson J, Chidel M (1999) Bat communities in a fragmented forest landscape on the southwest slopes of New South Wales, Australia. Biological Conservation, 88(3): 333-345.

Lee YF, McCracken GF (2005) Dietary variation of Brazilian free-tailed bats links to migratory populations of pest insects. Journal of Mammalogy 86(1): 67-76.

Legendre P, L Legendre (2012) Numerical ecology. Third English edition. Elsevier Science, Amsterdam, The Netherlands, (24): 989.

Lesiński G, Gryz JB (2012) How protecting a suburban forest as a natural reserve effected small mammal communities. Urban Ecosystems, 15(1):103-110.

Lim BK, Engstrom MD (2001) Species diversity of bats (Mammalia: Chiroptera) in Iwokrama Forest, Guyana, and the Guianan subregion: implications for conservation. Biodiversity and Conservation, 10:613-657.

Lima IP (2008) Espécies de morcegos (Mammalia, Chiroptera) registradas em parques nas áreas urbanas do Brasil e suas implicações no uso deste ambiente. In Ecologia de morcegos (NR, Reis AL, Peracchi e GASD, Santos Org.). Technnical books, Londrina p.71-85.

Lindenmayer DB, Hobbs RJ (2004) Fauna conservation in Australian plantation forests - a review. Biol. Conserv. 119: 151-168.

Loayza AP, Loiselle BA (2008) Preliminary information on the home range and movement patterns of Sturnira lilium (Phyllostomidae) in a naturally fragmented land- scape in Bolivia. Biotropica 40: 630-635.

Loureiro LO, Gregorin R (2015) Structure of a bat assemblage from a fragmented landscape in the state of minas gerais, southeastern Brazil.

Mac Nally R, Horrocks G, Bennett AF (2002) Nestedness in fragmented landscapes: birds of the boxironbark forests of south-eastern Australia. Ecography (25):651- 660.

MacAvoy S, Arneson L, Bassett E (2006) Correlation of metabolism with tissue carbon and nitrogen turnover rate in small mammals. Oecologia 150: 190-201.

Machado RB, Aguiar LMS, Bianchi A, Vianna RL, Santos AJB, Saito CH, Timmers JF (1997) Áreas de risco no entorno de unidades de conservação: estudo de caso da Estação Ecológica de águas Emendadas, Planaltina, DF, p64-73. In: Marinho- Filho J, Rodrigues F e Guimarães M (Eds.) Vertebrados da Estação Ecológica de Águas Emendadas. História natural e ecologia de um fragmento de cerrado do Brasil Central. Brasília, SEMATEC, IEMA, IBAMA, p 92. 
Machado RB, Ramos Neto MB, Harris MB, Lourival R, Aguiar LMS (2004) Análise de lacunas de proteção da biodiversidade no Cerrado. In: Anais IV Congresso Brasileiro de Unidades de Conservação. Fundação O Boticário de Proteção à Natureza, Curitiba, Brasil. pp 29-38.

Machado RB, Ramos Neto MB, Pereira P, Caldas E, Gonçalves D, Santos N, Tabor K, Steininger M (2004) Estimativas de perda da área do Cerrado brasileiro. Conservation International, Brasilia, p26.

Malcolm JR (1997) Biomass and diversity of small mammals in Amazonian forest fragments. In W. F Laurance and R. 0. Bierregaard Jr. (Eds.). Tropical forest remnants: ecology, management, and conservation of fragmented communities, University of Chicago Press, Chicago, Illinois pp 207221.

Maldonado-Coelho M, Marini MA (2004) Mixed-species bird flocks from Brazilian Atlantic forest: the effects of forest fragmentation and seasonality on their size, richness and stability. Biological Conservation 116(1): 19-26.

Manica LT, Telles M, Dias MM (2010) Bird richness and composition in a Cerrado fragment in the State of São Paulo. Brazilian Journal of Biology, 70(2): 243-254.

Marinho-Filho J (1985) Padrões de atividade e utilização de recursos alimentares por seis espécies de morcegos filostomídeos na Serra do Japi, Jundiaí, São Paulo (Doctoral dissertation, MSc. Dissertation. Universidade Estadual de Campinas, Campinas, Brazil).

Marinho-Filho J (1996) The brazilian cerrado bat fauna and its conservation. Chiroptera Neotropical 2(1): 37-39.

Marinho-Filho J (2012) The Brazilian Cerrado bat fauna and its Conservation. Chiroptera Neotropical 2(1): 37-39.

Marinho-Filho J, Sazima I (1998) Brazilian bats and conservation biology: a first survey. In: Kunz TH, Racey PA (eds.). Bat Biology and Conservation. Washington DC: Smithsonian Institution Press. Zoology Vol. 8, Walter de Gruyter. pp 282-294.

Marini MÂ (2001) Effects of forest fragmentation on birds of the cerrado region, Brazil. Bird Conservation International 11(01): 13-25.

Martinelli LA, Ometto JPHB, Ferraz ES, Victoria RL, Camargo PBC, Moreira Z (2009) Desvendando questões ambientais com isótopos estáveis. São Paulo, Oficina de Textos. p 130. 
Martins ES, Reatto A, Carvalho OAJ, Guimarães RF (2005) Geomorfologia da APA de Cafuringa. In: APA de Cafuringa: a última fronteira natural do Distrito Federal. Brasília: Secretaria de Meio Ambiente e Recursos Hídricos 2 (4): 48-52.

Marzzoco A, Torres BB (1999) Bioquímica básica. Guanabara kooga. p 360.

McKinney ML (2006) Urbanization as a major cause of biotic homogenization. Biological conservation, 127(3): 247-260.

Medellín RA, Equihua M, Amin MA (2000) Bat diversity and abundance as indicators of disturbance in Neotropical rainforests.Conservation Biology 14(6):1666-1675.

Mello MAR, Schittini GM (2014) Ecological analysis of three bat assemblages from conservation units in the Lowland Atlantic Forest of Rio de Janeiro, Brazil. Chiroptera Neotropical, 11(1-2): 206-210.

Metzger JP (1999) Estrutura da paisagem e fragmentação: análise bibliográfica. Anais da Academia Brasileira de Ciências (71): 435-463.

Metzger JP, Martensen AC, Dixo M, Bernacci LC, Ribeiro MC, Teixeira AMG, Pardini R (2009) Timelag in biological responses to landscape changes in a highly dynamic Atlantic forest region. Biological Conservation 142:1188-1177.

Metzger MJ (2005) European vulnerability to global change, a spatially explicit and quantitative assessment. PhD thesis, Wageningen University. p 192.

Metzger, JP (2002) Bases biológicas para a definição de Reservas Legais. Ciência Hoje 31(183): 4849.

Meyer CFJ, Kalko EKV (2008) Assemblage- level responses of phyllostomid bats to tropical forest fragmentation: land-bridge islands as a model system. Journal of Biogeography 35(9):17111726.

Miller G (1907) The families and genera of bats. U.S. Natl. Mus. Bull 57:1-282.

Miron LL, Herrera LG, Ramírez N, Hobson KA (2006) Effect of diet quality on carbon and nitrogen turnover and isotopic discrimination in blood of a New World nectarivorous bat. Journal of Experimental Biology 209: 541-548.

Mittermeier RS, Myers N, Gil PR, Mittermeier CG (1999) Hotspots: earth's biologically richest and most endangered terrestrial ecoregions. Cidade do México, México, Cemex Conservation International. 
Mizutani H, McFarlane DA, Kabaya Y (1992) Nitrogen and Carbon Isotope Study of Bat Guano Core from Eagle Creek Cave, Arizona, USA. Journal of the Mass Spectrometry Society of Japan, 40(1), 57-65.

Mooney HA, Ehleringer JR (1997) Photosynthesis p. 1-27. In: Crawley MJ Ed. Plant Ecology. Second Edition p. 717.

Morato EF, Campos LDO (1993) Efeitos da fragmentação florestal sobre vespas e abelhas solitárias em uma área da Amazônia Central (Doctoral dissertation, Universidade Federal de Viçosa. pp 429-444.

Muñoz-Lazo, FJJ (2013) Efeito da fragmentação no metabolismo energético e nível trófico em duas espécies de morcegos frugívoros, Artibeus lituratus e Carollia perspicillata (Chiroptera: Phyllostomidae). 56 f. Dissertação - (mestrado) - Universidade Estadual Paulista, Instituto de Biociências de Rio Claro, 2013. Disponível em: <http://hdl.handle.net/11449/108741>.

Murcia C (1995). Edge effects in fragmented forests: implications for conservation. Trends in Ecology \& Evolution 10(2):58-62.

Myers N, Mittermeier RA, Mittermeier CG, Fonseca GAB, Kent J (2000) Biodiversity hotspots for conservation priorities. Nature (403): 853-858.

Nardoto GB, Godoy PB, Ferraz ESB, Ometto JPHB, Martinelli LA (2006a) Stable carbon and nitrogen isotopic fractionation between diet and swine tissues. Sci. Agri. 63: 579-82.

Nardoto GB, Silva S, Kendall C et al. (2006b) Geographical Patterns of Human Diet Derived from Stable-Isotope Analysis of Fingernails. Am. J. Phys. Anthropol. 131: 137- 46.

Nassar JM, Beck H, Sternberg LSL, Fleming TH (2003) Dependence on cacti and agaves in nectarfeeding bats from venezuelan arid zones. J. Mamm. 84: 106-116.

Nogueira MR, de Lima IP, Moratelli R, da Cunha VT, Gregorin R, Peracchi AL (2014) Checklist of Brazilian bats, with comments on original records. Check List, 10(4), 808-821.

Nogueira MR, Peracchi AL (2003) Fig-seed predation by 2 species of Chiroderma: discovery of a new feeding strategy in bats. Journal of Mammalogy 84(1): 225- 233.

Nogueira MR, Tavares VC, Peracchi AL (2003) New records of Uroderma magnirostrum Davis (Mammalia, Chiroptera) from southeastern Brazil, with comments on its natural history. Revista Brasileira de Zoologia 20(4): 691-697. 
Norberg UM, Rayner JMV (1987) Ecological morphology and flight in bats (Mammalia; Chiroptera): wing adaptations, flight performance, foraging strategy and echolocation. Philos. Trans. R. Soc. Lond. B: Biol. Sci. 316: 335-427.

Novaes RLM, Rosa DTC, Vrcibradic D, Avilla LS (2015) Bat assemblages from three Atlantic Forest fragments in Rio de Janeiro state, Southeastern Brazil. Biodiversity Data Journal (3): e4404. doi:10.3897/BDJ.3.e4404.

O'Brien AM, Ettinger AK, HilleRisLambers J (2012) Conifer growth and reproduction in urban forest fragments: Predictors of future responses to global change? Urban Ecosystems 15(4): 879-891.

Oprea M, Mendes P, Vieira TB, Ditchfield AD (2009) Do wooded streets provide connectivity for bats in an urban landscape? Biodivers. Conserv. (18): 2361-2371.

Paglia A, Fonseca GAB, Rylands AB (2012) Lista anotada dos mamíferos do Brasil. 2ª edição. Occasional Papers in Conservation Biology (6):1-76.

Parron LM, Bustamante MMC, Camargo PB (2004) Composição isotópica de carbono e nitrogênio em solos e plantas de uma Mata de Galeria: efeito do gradiente topográfico. Embrapa Cerrados. 127: 1-24.

Pavan AC, Martins F, Santos FR, Ditchfield A, Redondo RA (2011) Patterns of diversification in two species of short-tailed bats (Carollia Gray, 1838): the effects of historical fragmentation of Brazilian rainforests. Biological Journal of the Linnean Society, 102(3): 527-539.

Pedro WA, Geraldes MP, Lopez GG, Alho CJR (1995) Fragmentação de habitat e a estrutura de uma taxocenose de morcegos em São Paulo (Brasil). Chiroptera Neotropical 1(1): 4-6.

Pedro WA, Taddei VA (1997) Taxonomic assemblage of bats from Panga Reserve, southeastern Brazil: abundance patterns and trophic relations in the Phyllostomidae (Chiroptera). Boletim do Museu de Biologia Mello Leitão (6) 3- 21.

Pereira AL, Benedito E (2007) Isótopos estáveis em estudos ecológicos: métodos, aplicações e perspectivas. Rev.biociência, Taubaté (13):1-2.

Perini FA., Tavares VC, Nascimento CMD (2003) Bats from the city of Belo Horizonte, Minas Gerais, Southeastern Brazil. Chiropt. Neotrop. (9):1-2.

Peterson BJ, Fry B (1987) Stable isotopes in ecosystem studies. Annual Review of Ecology and Systematics 18:293-320. 
Pina S, Meyer C, Zortéa M (2013) A comparison of habitat use by bats in natural forest fragments and Eucalyptus plantations in Brazilian Savanna. Chiroptera Neotropical 19(3): 14-30.

Portella AS (2010) Morcegos cavernícolas e relações parasita-hospedeiro com moscas Estreblídeas em cinco cavernas do Distrito Federal. 61 f.: Dissertação (Mestrado em Ecologia) - Universidade de Brasília, Brasília.

Posey D (1984) Os Kayapó e a natureza. Ciência Hoje, Rio de Janeiro, 2(12): 35-41.

Ramos R, Gonza'lez-Solı's J (2012) Trace me if you can: the use of intrinsic biogeochemical markers in marine top predators. Front Ecol Environ 10(5): 258- 266.

Ratter JA, Ribeiro JF, Bridgewater S (1997) The Brazilian cerrado vegetation and threats to its biodiversity. Annals of Botany 80(3): 223-230.

Reis NR (1984) Estrutura de comunidade de morcegos na região de Manaus, Amazonas. Rev Bras Biol 44(3):247-254.

Reis NR, et al. (2003) What is better for maintaining the richness of bat (Mammalia, Chiroptera) species: a large forest fragment or many small fragments? Revista Brasileira de Zoologia 20(2): 225-230.

Reis NR, Gallo PH, Peracchi AL, Lima IP, Fregonezi MN (2012) Sensitivity of populations of bats Mammalia: Chiroptera) in relation to human development in northern Paraná, southern Brazil. Brazilian Journal of Biology 72(3): 511-518.

Reis NR, Lima IP, Peracchi AL (2002) Morcegos (Chiroptera) da área urbana de Londrina Paraná Brasil. Rev. Bras. Zool. 19(3): 739-746.

Rex K, Czaczkes BI, Michener R, Kunz TH, Voigt CC (2010) Specialization and omnivory in diverse mammalian assemblages. Ecoscience 17(1): 37-46.

Rex K, Michener R, Kunz TH, Voigt CC (2011) Vertical stratification of Neotropical leaf-nosed bats (Chiroptera: Phyllostomidae)revealedbystablecarbonisotopes. Journal of Tropical Ecology 27:211-222.

Reynolds JC, Aebisher NJ (1991) Comparisons and quantification of carnivore diet by fecal analyses: a critique, with recommendations, based on a study on the fox Vulpes vulpes. Mamm. Rev. 21:97122.

Ribeiro JF e Walter BMT (1998) Fitofisionomias do bioma Cerrado. P. 87-166. In: Sano, SM e Almeida, SPD (Eds.). Cerrado: Ambiente e flora. Brasília, EMBRAPA 556p. 
Ribeiro JF, Walter BMT (2008) As principais fitofisionomias do bioma Cerrado. In: Sano, SM, Almeida SP, Ribeiro JF. Cerrado: Ecologia e Flora. Planaltina: Embrapa Cerrados; Brasília: Embrapa Informação Tecnológica, (1): 406.

Ricklefs RERE (2001) The economy of nature (No. Sirsi i9780716738831).

Ripperger SP, Tschapka M, Kalko EK, Rodriguez-Herrera B, Mayer F (2013) Life in a mosaic landscape: Anthropogenic habitat fragmentation affects genetic population structure in a frugivorous bat species. Conservation Genetics, 14(5): 925-934.

Rodrigues FHG, Silveira L, Jácomo ATA, Carmignotto AP, Bezerra AMR, Coelho DC, ... Hass A (2002) Composição e caracterização da fauna de mamíferos do Parque Nacional das Emas, Goiás, Brasil. revista brasileira de zoologia, 19(2): 589-600.

Rodrigues MGR, Bredt A, Uieda W (1994) Arborização de Brasília, Distrito Federal, e possíveis fontes de alimento para morcegos fitófagos. Anais do II Congresso Brasileiro Arborização Urbana (2): 311-326.

Rodríguez-Durán A, Otero W (2011) Species richness and diversity of a West Indian bat assemblage in a fragmented ecosystem. Acta Chiropterologica, 13(2), 439- 445.

Roswag A, Becker NI, Encarnação JA (2014) Factors influencing stable nitrogen isotope ratios in wing membranes of insectivorous bat species: A field study. Mammalian Biology-Zeitschrift für Säugetierkunde79(2): 110-116.

Sala OE, Chapin, FS, Armesto JJ, Berlow E, Bloomfield J, Dirzo R, Wall DH (2000) Global biodiversity scenarios for the year 2100. Science 287(5459): 1770-1774.

Salgado SS, Motta PC, Aguiar LMS, Nardoto GB (2014) Tracking dietary habits of cave arthropods associated with deposits of hematophagous bat guano: A study from a neotropical savanna. Austral Ecology 39 (5): 560-566.

Salgado SS, Motta PC, Souza Aguiar LM, Nardoto GB (2014) Tracking dietary habits of cave arthropods associated with deposits of hematophagous bat guano: A study from a neotropical savanna. Austral Ecology 39(5): 560-566.

Salvarina I, Yohannes E, Siemers BM, Koselj K (2013) Advantages of using fecal samples for stable isotope analysis in bats: evidence from a triple isotopic experiment. Rapid Communications in Mass Spectrometry, 27(17): 1945-1953. 
Sano EE, Rosa R, Brito JLS, Ferreira LG (2008) Mapeamento semidetalhado do uso da terra no bioma Cerrado. Pesquisa Agropecuária Brasileira, 43(1): 153- 156.

Saunders DS, Hobbs RJ, Margules CR (1991) Biological consequences of ecosystem fragmentation: A review. Conservation Biology (5): 18-32.

Sazima I, Fischer WA, Sazima M, Fischer E (1994) The fruit bat Artibeus lituratus as a forest and city dweller. Ciênc. Cult. 46(3):164-168.

Schondube JE, Herrera-M LG, del Rio CM (2001) Diet and the evolution of digestion and renal function in phyllostomid bats. Zoology, 104(1): 59-73.

Schulze MD, Seavy NE, Whitacre DF (2000) A comparison of the phyllostomid bat assemblages in undisturbed Neotropical forest and in forest fragments of a slash- and-burn farming mosaic in Peten, Guatemala. Biotropica 32: 174-184.

Shapiro JT, Bordignon MO (2014) Bat (Chiroptera) assemblages in three Cerrado fragments of Mato Grosso do Sul, southwestern Brazil. Check List 10(6): 1380- 1386.

Siegel S (1975). Estatística não-paramétrica para as ciências do comportamento. São Paulo: McGrawHill, p12.

Silva MMS, Harmani NMS, Gonçalves EFB, Uieda W (1996) Bats from the metropolitan region of São Paulo, Southeastern Brazil. Chiropt. Neotrop. (2):39- 41.

Silvano DL, Colli GR, Dixo MBO, Pimenta BVS, Wiederhecker HC (2003) Anfíbios e répteis. In: Rambaldi, Denise Marçal, e Daniela América Suárez de Oliveira. Fragmentação de ecossistemas: causas, efeitos sobre a biodiversidade e recomendações de políticas públicas. Brasília, DF: Ministério do Meio Ambiente, Secretaria de Biodiversidade Florestas 7:183-200.

Simmons NB (1996) A new species of Micronycteris (Chiroptera: Phyllostomidae) from Northeastern Brazil, with comments on phylogenetic relationships. Am. Mus. Novit. 3158:1-34.

Smith JD (1976) Chiropteran evolution. In Biology of Bats of the New World Family Phyllostomatidae (Part I) (Baker, R.J. et al., eds) 49-69, Texas Tech Press.

Sousa RF, Venere PC, Faria KC (2013) Bats in forest remnants of the Cerrado savanna of eastern Mato Grosso, Brazil. Biota Neotropica 13(2): 236-241.

Speakman JR., Thomas DW (2003) Physiological ecology and energetics of bats. In: Kunz TH, Fenton MB (Eds.) Bat Ecology. The University of Chicago Press, Chicago, pp. 430-490. 
Stoner KE (2005) Phyllostomid Bat Community Structure and Abundance in Two Contrasting Tropical Dry Forests. Biotropica 37(4): 591-599.

Stouffer PC, Bierregaard RO (1995) Effects of forest fragmentation on understory hummingbirds in Amazonian Brazil. Conservation Biology 9(5): 1085-1094.

Straube FC, Bianconi GV (2002) Sobre a grandeza e a unidade utilizada para estimar esforço de captura com utilização de redes-de-neblina. Chiroptera Neotropica 8(1-2): 150-152.

Struebig MJ, Kingston T, Petit EJ, Le Comber SC, Zubaid A, Mohd-Adnan A, Rossiter SJ (2011) Parallel declines in species and genetic diversity in tropical forest fragments. Ecology Letters 14(6): 582-590.

Taddei VA (1979) Phyllostomidae (Chiroptera) do Norte-Ocidental do Estado de São Paulo. III Stenodermatinae. Ciência e Cultura, São Paulo, 31 (8): 900-914.

Taddei VA, Reis NR (1980) Notas sobre alguns morcegos da llha de Maracá, Território Federal de Roraima (Mammalia, Chiroptera). Acta Amaz 10(2):363-368.

Taddei VA, Vizotto LD, Sazima IVAN (1983) Uma nova espécie de Lonchophylla do Brasil e chave para identificação das espécies do gênero (Chiroptera, Phyllostomidae)." Ciência e Cultura 35(5): 625-629.

Teeling EC, Springer MS, Madsen O, Bates P, O'brien SJ, Murphy WJ (2005) A molecular phylogeny for bats illuminates biogeography and the fossil record. Science 307(5709):580-584.

Theodore H, Fleming e Vinicio J. Sosa (1994) Effects of Nectarivorous and Frugivorous Mannals on Reproductive Success of Plants. Journal of Mammalogy 75 (4): 845-851.

Thewissen JGM, Babcock SK (1992) The origin of flight in bats. BioScience 340-345.

Thomas DW, Marshall AG (1984) Reproduction and growth in three species of West African fruit bats. J Zool (Lond), 202: 265281.

Tieszen LL, Boutton TW, Tesdahl KG, Slade NA (1983) Fractionation and turnover of stable carbon isotopes in animal tissues: Implications for d13C analysis of diet. Oecologia 57:32-37.

Tilman D, Fargione J, Wolff B, D'Antonio C, Dobson A, Howarth R, Schindler D, Schlesinger WH, Simberloff D, Swackhamer D (2001) Forecasting agriculturally driven global environmental change. Science (292): 281-284. 
Trevelin LC, Silveira M, Port-Carvalho M, Homem DH, Cruz-Neto AP (2013) Use of space by frugivorous bats (Chiroptera: Phyllostomidae) in a restored Atlantic forest fragment in Brazil. Forest Ecology and Management (291):136-143.

Uieda W, Chaves ME, Santos CF (2006) Guia das principais espécies de morcegos brasileiros. Botucatu, São Paulo, 71p.

Van Valen L (1979) The evolution of bats. Evol. Theory 4:104-121.

Vandermeer J, Perfecto I (2007) The agricultural matrix and a future paradigm for conservation. Conservation Biology (21): 274-277.

Viana VM (1990) Biologia e manejo de fragmentos florestais atuais. In: Congresso Brasileiro Florestal, 6. Campos do Jordão. Anais...Campos do Jordão: SBS/SBEF p113-118.

Vitousek PM, Mooney HA, Lubchenko J, Melillo JM (1997) Human domination of Earth's ecosystems. Sciense (277): 494-499.

Vizotto LD, Taddei VA (1973) Chave para determinação de quirópteros brasileiros. Bol. Ciências. $(1): 1-72$.

Voigt CC (2010) Insights into strata use of forest animals using the canopy effect. Biotropica 42:634-637.

Voigt CC, Kelm DH (2006) Host preferences of the common vampire bat Desmodus rotundus assessed by stable isotopes. Journal of Mammalogy 87:1-6.

Voigt CC, Matt F (2004) Nitrogen stress causes unpredictable enrichments of $15 \mathrm{~N}$ in two bat species. J. Exp. Biol. 207: 1741-1748.

Voigt CC, Matt F, Michener R, Kunz TH (2003) Low turnover rates of carbon isotopes in tissues of two nectar-feeding bat species. J. Exp. Biol. 206: 1419-1427.

Voigt CC, Rex K, Michener R, Speakman JR (2008) Nutrient routing in omnivorous animals tracked by stable carbon isotopes in tissue and exhaled breath. Oecologia 157:31-40.

Voigt CC, Speakman JR (2007) Nectar-feeding bats fuel their high metabolism directly with exogenous carbohydrates. Functional Ecology 21(5): 913-921.

Voigt CC, Voigt-Heucke SL, Kretzschmar AS (2012) Isotopic evidence for seed transfer from successional areas into forests by short-tailed fruit bats (Carollia spp.; Phyllostomidae). Journal of Tropical Ecology 28(02): 181-186. 
Weins JA (1989) The ecology of bird communities. Cambridge. Cambridge University Press, XVIII, p.539.

Wiens JA, Chr N, Van Horne B, Ims RA (1993) Ecological mechanisms and landscape ecology. Oikos, p 369-380.

Wilcove DS, McLellan CH, Dobson AP (1986) Habitat fragmentation in the temperate zone. In: Soule $\mathrm{ME}$, editor. Conservation biology: the science of scarcity and diversity. Sinauer Associates, Sunderland, Massachusetts. pp 237-256.

Williams SL, Genoways HH (2007) Subfamily Phyllostominae Gray, 1825 from Mammals of South America. Mammalogy Papers: University of Nebraska State Museum. Paper 113.

Willig MR (1983) Composition, microgeographic variation, and sexual dimorphism in Caatinga and Cerrado bat communities from northeast Brazil. Bulletin of Carnegie Museum of Natural History, Pittsburgh 23: 1-131.

Willig MR, Presley SJ, Bloch CP, Hice CL, Yanoviak SP, Díaz MM, Weaver SC (2007) Phyllostomid bats of lowland Amazonia: effects of habitat alteration on abundance. Biotropica 39(6): 737-746. York HA, Billings SA (2009) Stable-isotope analysis of diets of short-tailed fruit bats (Chiroptera: Phyllostomidae: Carollia). Journal of Mammalogy 90(6): 1469-1477.

Zortéa M, Alho CJR (2008) Bat diversity of a Cerrado habitat in central Brazil. Biodivers. Conserv. 17:791-805.

Zortéa M, Chiarello AG (1994) Observations on the big fruit eating bat, Artibeus lituratus, in an urban reserve of south-east Brazil. Mammalia 58:665-670. 